$$
\text { Conf }-941101 \cdots 5
$$

GA-A21871

\title{
ADVANCES IN THE SIMULATION OF TOROIDAL GYRO LANDAU FLUID MODEL TURBULENCE
}

\author{
by \\ R.E. WALTZ, G.D. KERBEL, J. MILOVICH, \\ and G.W. HAMMETT
}

DECEMBER 1994 


\section{DISCLAIMER}

This report was prepared as an account of work sponsored by an agency of the United States Government. Neither the United States Government nor any agency thereof, nor any of their employees, makes any warranty, express or implied, or assumes any legal liability or responsibility for the accuracy, completeness, or usefulness of any information, apparatus, produce, or process disclosed, or represents that its use would not infringe privately owned rights. Reference herein to any specific commercial product, process, or service by trade name, trademark, manufacturer, or otherwise, does not necessarily constitute or imply its endorsement, recommendation, or favoring by the United States Government or any agency thereof. The views and opinions of authors expressed herein do not necessarily state or reflect those of the United States Government or any agency thereof. 


\title{
ADVANCES IN THE SIMULATION OF TOROIDAL GYRO LANDAU FLUID MODEL TURBULENCE
}

\author{
by \\ R.E. WALTZ, G.D. KERBEL, "J. MILOVICH, ${ }^{*}$ \\ and G.W. HAMMETT ${ }^{\dagger}$
}

This is a preprint of a paper to be presented at the 36th Annual Meeting Division Plasma Physics, November 7-11, 1994, Minneapolis, Minnesota, and to be printed in the Proceedings.

\section{DISCLAIMER}

Portions of this document may be illegible in electronic image products. Images are 


\section{DISCLAIMER}

Portions of this document may be illegible in electronic image products. Images are produced from the best available original document. 


\title{
ADVANCES IN THE SIMULATION OF TOROIDAL GYRO LANDAU FLUID MODEL TURBULENCE
}

\author{
by \\ R.E. WALTZ, G.D. KERBEL, ${ }^{*}$ J. MILOVICH, ${ }^{*}$ \\ and G.W. HAMMETT ${ }^{\dagger}$
}

This is a preprint of a paper to be presented at the 36th Annual Meeting Division Plasma Physics, November 7-11, 1994, Minneapolis, Minnesota, and to be printed in the Proceedings.

Work supported by U.S. Department of Energy

Grant No. DE-FG03-92ER54150 and Contract Nos. W-7405-ENG-48 and DE-AC02-76CHO3O73

*NERSC at Lawrence Livermore National Laboratory

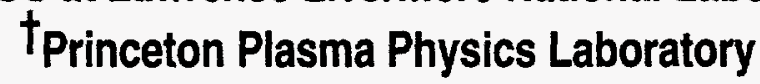

DISTRIBUTION OF THIS DOCUMENT IS UNLIMITED

\section{GENERAL ATOMICS PROJECT 3938 DECEMBER 1994}




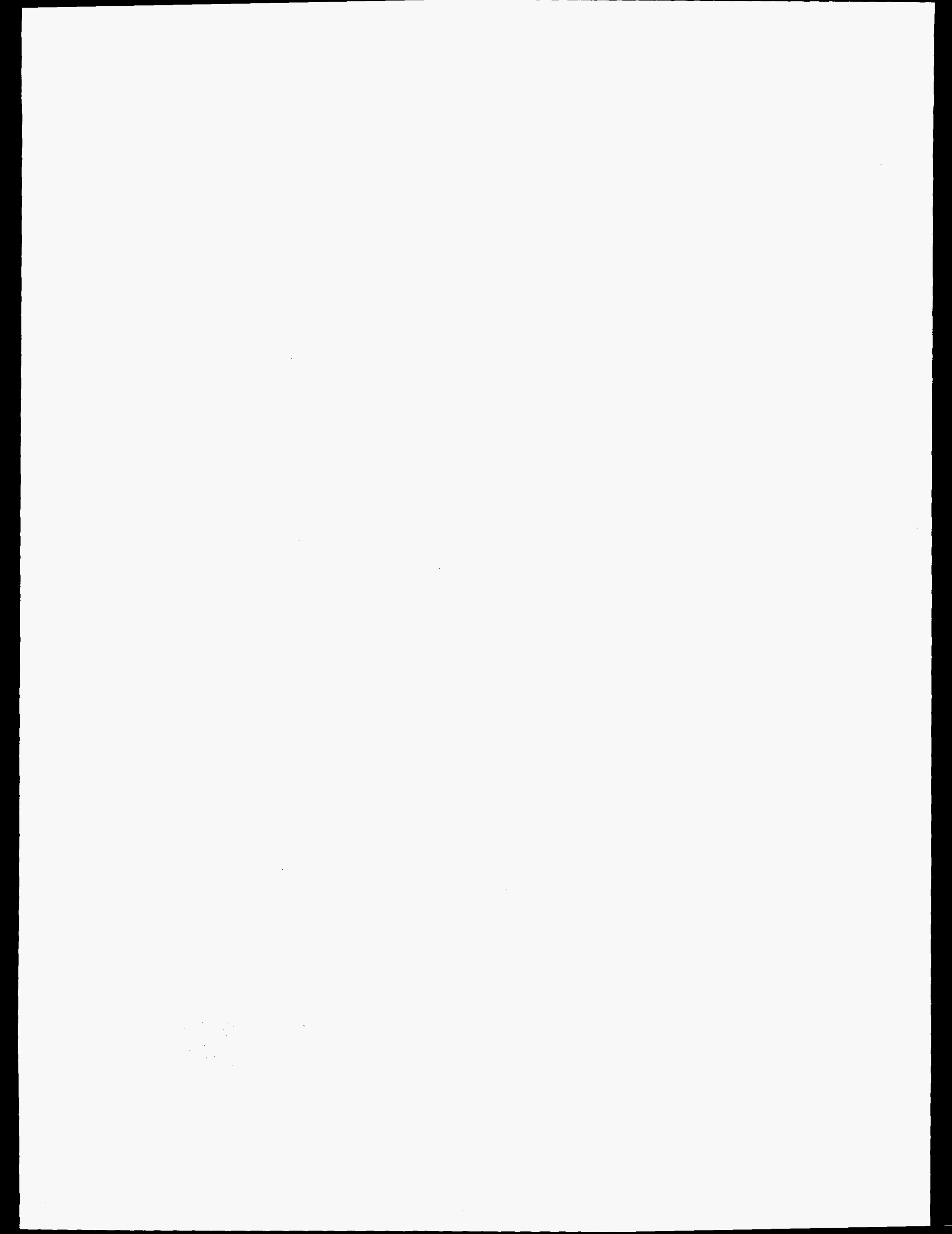




\section{ABSTRACT}

The gyro-Landau fluid (GLF) model equations for toroidal geometry [R.E. Waltz, R.R. Dominguez, and G.W. Hammett, Phys. Fluids B 4, (1992) 3138] have been recently applied to the study ion temperature gradient (ITG) mode turbulence using the 3D nonlinear ballooning mode representation (BMR) outlined in [R.E. Waltz, G.D. Kerbel, and J. Milovich, Phys. Plasmas 1, 2229 (1994)]. The present paper extends this work by treating some unresolved issues concerning ITG turbulence with adiabatic electrons. Although eddies are highly elongated in the radial direction long time radial correlation lengths are short and comparable to poloidal lengths. Although transport at vanishing shear is not particularly large, transport at reverse global shear, is significantly less. Electrostatic transport at moderate shear is not much effected by inclusion of local shear and average favorable curvature. Transport is suppressed when critical $E \times B$ rotational shear is comparable to the maximum linear growth rate with only a weak dependence on magnetic shear. Self consistent turbulent transport of toroidal momentum can result in a transport bifurcation at suffciently large $r /(\mathrm{Rq})$. However the main thrust of the new formulation in the paper deals with advances in the development of finite beta GLF models with trapped electron and BMR numerical methods for treating the fast parallel field motion of the untrapped electrons. 



\section{CONTENTS}

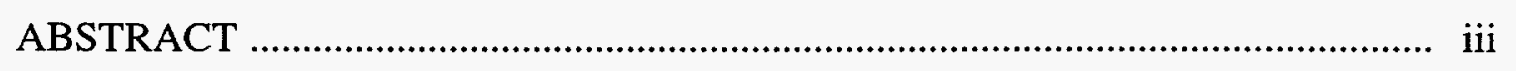

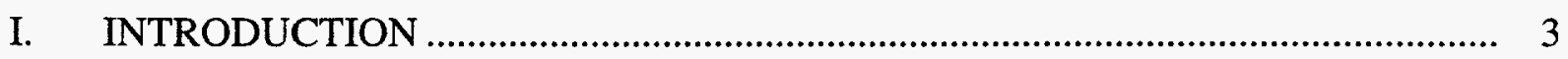

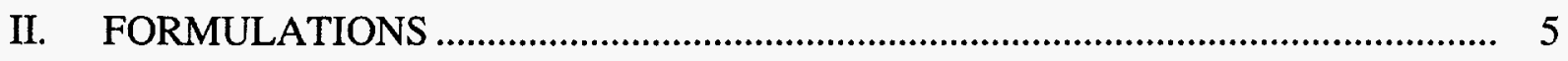

A. Finite Beta GLF Models with Electron Physics …....................................... 5

B. Nonlinear Ballooning Mode Representation ................................................ 10

C. Special Numerical Methods for Simulation of Electron Models......................... 11

D. Rotation Shear Stabilization and Rotation Momentum Transport ....................... 13

III. TOROIDAL ITG TURBULENCE WITH ADIABATIC ELECTRONS …............... 15

A. Long Radial Wavelength Structure and Short Correlation Lengths ................... 15

B. Transport a Reverse Global Shear, with Local Shear, and Average

Favorable Curvature ............................................................................ 18

C. Critical Rotational Shear Stabilization at Weak Magnetic Shear ....................... 20

D. Turbulent Rotational Momentum Transport and Transport Bifurcation ............. 22

IV. LINEAR TEST OF FINITE BETA TRAPPED ELECTRON GLF MODELS ........... 25

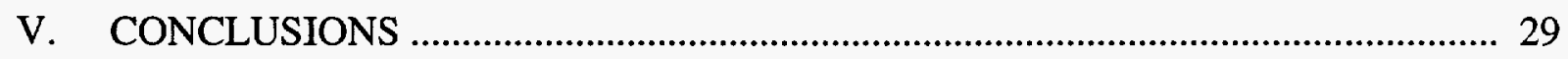

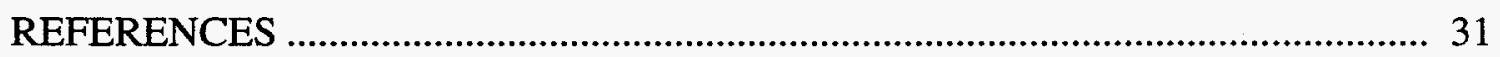

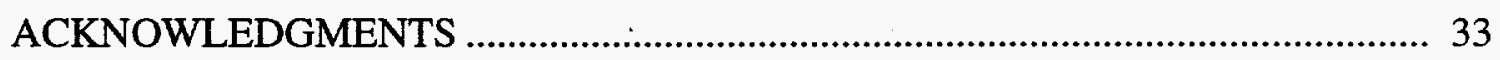




\section{FIGURES}

1. Radial (a) and poloidal (b) correlation functions at various time averaging intervals

2. Diffusion at both positive and negative shear

3. Maximum growth rate (a) and diffusion (b) versus Shafranov shift $\alpha$

4. Critical Doppler shear rate versus shear $\hat{s}$

5. Low $\mathrm{r} /(\mathrm{rq})(\mathrm{a})$ high $\mathrm{r} /(\mathrm{Rq})(\mathrm{b})$ momentum bifurcation onset

6. Trapped electron model growth rate spectrum versus $\beta_{\mathrm{c}}$

7. Trapped electron model growth rate spectrum $\beta_{\mathrm{e}}=0$ (a) $\beta_{\mathrm{e}}=0.004$, (b) with $\beta_{\text {e-crit }}$ at 0.0055 26

8. Trapped electron model growth rate spectrum versus collision frequency $\mathrm{v}$ at $\mathrm{k}_{\mathrm{y}}=0.3$ 


\section{INTRODUCTION}

This paper describes some recent advances in the simulation gyro-Landau (GLF) model equations for toroidal geometry as formulated by Waltz, Dominguez, and Hammett ${ }^{1}$ and applied to the study of ion temperature gradient mode (ITG) turbulence using a 3D nonlinear ballooning mode representation (BMR) outlined in a very recent paper by Waltz, Kerbel, and Milovich. ${ }^{2}$ The present paper is intended to be read in close conjunction with the latter reference which dealt exclusively with the ITG turbulence assuming adiabatic (near Boltzmann) electrons in the electrostatic limit. Reference 2 should be consulted for numerous references to earlier and contemporary work on the simulation of ITG turbulence. The key results were that the toroidal turbulence is highly ballooning and the toroidal transport levels are more than twenty-fold larger than slab levels. The scaling of diffusion with shear $\hat{s}$, safety factor $q$ and temperature gradient is found to be similar to the scaling of the linear mixing length model at least near threshold at moderate to strong shear $(1<\hat{s}<2)$. The mixing length diffusion is simply the product of growth rate for the maximally unstable ballooning mode and the square linear mode width [DML $=\gamma_{\max } \Delta_{x}^{2}$ where $\Delta_{x}=1 /\left(\mathrm{k}_{\mathrm{y}} \hat{s} \theta_{\mathrm{rms}}\right)$ with $\mathrm{k}_{\mathrm{y}}$ the poloidal wave number of maximal growth and its poloidal extent $\theta_{\mathrm{rms}}$. Diffusion increases with $q$ and decreases with $\hat{s}$ but remains finite to vanishing shear $(0<\hat{s}<1)$. No evidence of subcritical turbulence was found. Variations in the relative gyroradius $\left(\rho_{\mathrm{S}} / \mathrm{a}\right)$ showed no long wave condensation or deviations from gyro-Bohm scaling. The simulations in this mixing length regime were characterized in Ref 2 . by a diffusion scaling $\chi=0.5(q / \hat{s})^{2}\left(c_{s} \rho_{s}^{2} / R\right)\left(R / L_{T}-R / L_{T_{-}} c r i t\right)$. There appears also to be a very strong temperature gradient regime in which the turbulence condenses to longer wave numbers and diffusion is weakly dependent on the driving gradient in contrast to the linear mixing length rule. A subsequent study by Dorland, Beer, Kotschenreuther, et al. ${ }^{3}$ using many more simulations and a more careful accounting of the variations of the critical gradient ratio $R / L_{T_{-}}$crit with $q$ and $\hat{s}$ as well as noting the $\left(T_{i} / T_{e}\right)$ dependence, showed that the weak shear regime and the strong temperature regime could be better described by a more general formula 
$\chi \propto[q /(2+\hat{s})]\left[c_{s} \rho_{s}^{2} / R\right]\left(T_{i} / T_{e}\right)^{1 / 2}\left(R / L_{T}-R / L_{T_{-}} c r i t\right)^{1 / 2}$. A key result of Ref. 2 and other recent work 4,5 has been that nonlinearly generated and linearly stable $n=0$ "radial modes" provide stabilizing small scale $E \times B$ sheared rotations which can reduce the transport ten-fold in comparison to neglecting them. In addition the equilibrium scale $E \times B$ sheared rotation causes the transport to vanish if the Doppler shear rate exceeds the maximum linear driving rate (including the parallel shear drive).

We return to electrostatic ITG turbulence with adiabatic electrons to treat several remaining issues not thoroughly discussed in Ref. 2: How to interpret the long wave structures apparent in instantaneous potential contour plots; the behavior of turbulence with reverse shear, Shafranov shift (or local shear), and magnetic well; scaling of the critical Doppler rotation shear for vanishing transport in the weak magnetic shear limit. And finally we treat self-consistent rotational shear stabilization and the transport of toroidal momentum leading to a momentum transport bifurcation.

The main thrust of the new formulation in the paper however deals with advances in the development of GLF models and nonlinear BMR numerical methods for relaxing the adiabatic electron assumption and treating the electron physics at finite beta. This includes trapped and untrapped electron fluid models with collisional exchange and inclusion of electromagnetic terms allowing a treatment of turbulence approaching the ideal MHD beta limit. While we believe the models and numerical methods are well in hand, at present we can only test the models linearly. To do this we have made extensive use of Kotschenreuther's gyrokinetic stability (GKS) ballooning mode stability code. 6

The outline of the paper is as follows: Section II deals with the complete formulation of the electromagnetic models with trapped electrons including the nonlinear equations of motion, the $E \times B$ and magnetic flutter transport equations, a review of the methods for the nonlinear BMR, and a description of the special implicit numerical methods required to handle the fast motion of 
the passing electrons. Section III treats the remaining issues of ITG turbulence with adiabatic electrons. Finally Section IV numerically illustrates the fidelity of the new GLF electromagnetic trapped-untrapped electron models with respect to the GKS code and discusses the special physics of $n=0$ radial modes with non-adiabatic electron physics. 


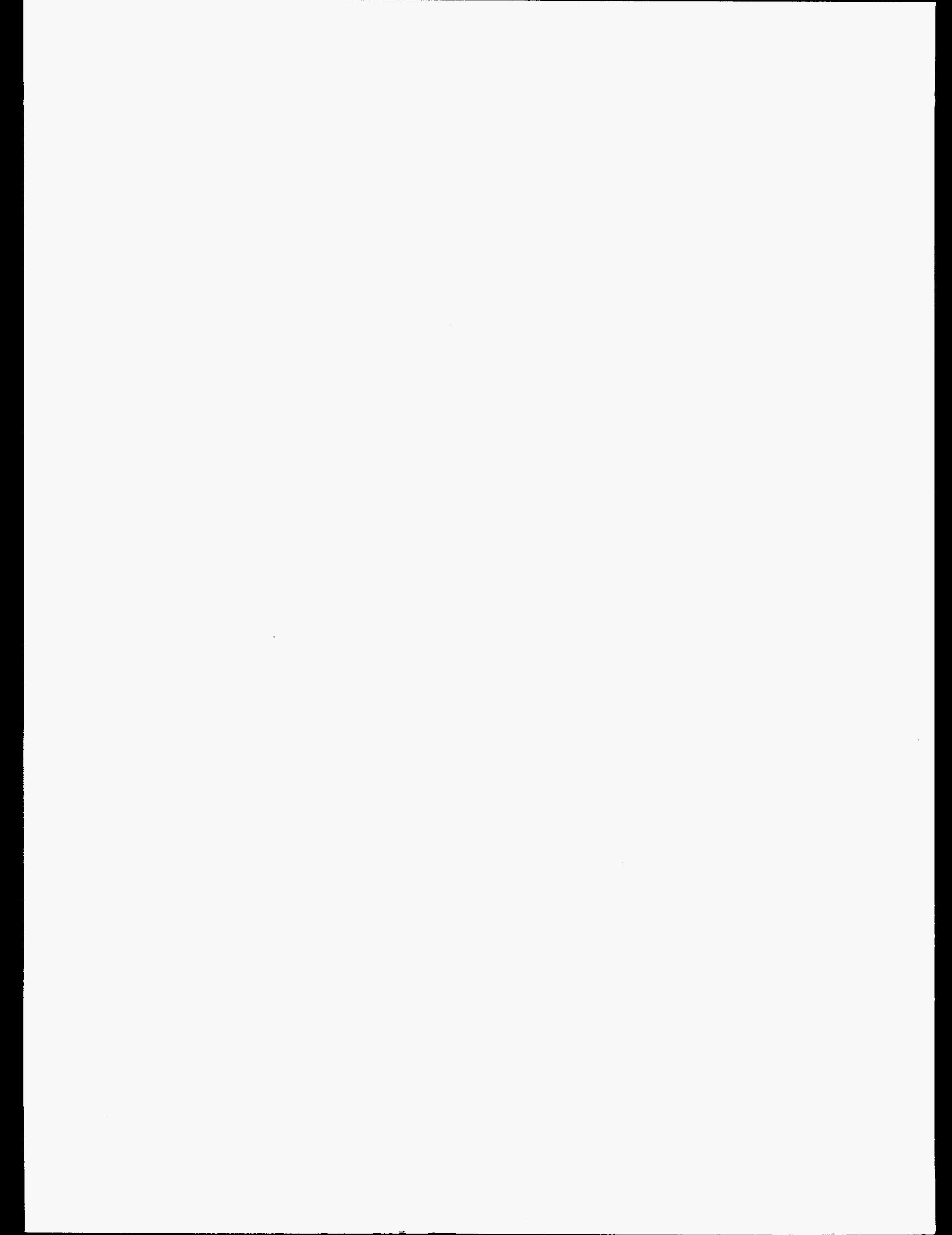




\section{FORMULATIONS}

\section{A. Finite beta GLF models with electron physics}

For purely passing particle with no consideration of the mirror force, generalization of the electrostatic toroidal GLF model ${ }^{1}$ to finite beta is straightforward. We need only include the parallel magnetic vector potential in the parallel momentum equations

$$
\begin{aligned}
& \mathrm{dN}_{\mathrm{k}}^{\mathrm{s}} / \mathrm{dt}=-\mathrm{i} \omega_{*}\left[\left(1_{\mathrm{s}}-\eta_{\mathrm{s}}\right) \phi_{1 k}^{s}+\eta_{\mathrm{s}} \phi_{2 k}^{s}\right]+\mathrm{i} \omega_{\mathrm{D}} \phi_{12 \mathrm{k}}^{\mathrm{s}}-\mathrm{i} \tilde{k}_{\|} \mathrm{U}_{\mathrm{k}}^{\mathrm{s}} \\
& +\mathrm{ie}_{\mathrm{s}} \omega_{D} \tau^{-1}\left(\mathrm{P}_{l \mathrm{kk}}+\mathrm{P}_{\perp \mathrm{k}}\right) / 2 \\
& \mathrm{dU}_{\mathrm{k}}^{\mathrm{s}} / \mathrm{dt}=-\mathrm{i} \tilde{k}_{\| 1} \mathrm{M}_{\mathrm{s}}^{-1}\left(\tau_{\mathrm{s}}^{-1} \mathrm{P}_{\| \mathrm{k}}^{\mathrm{s}}+\mathrm{e}_{\mathrm{s}} \phi_{1 \mathrm{k}}^{\mathrm{s}}\right) \\
& -\mathrm{M}_{\mathrm{s}}^{-1}\left(\beta_{\mathrm{e}} / 2\right)\left[\mathrm{e}_{\mathrm{s}} \partial \mathrm{A}_{1 \mathrm{k}}^{\mathrm{s}} / \partial \mathrm{t}-\mathrm{i} \omega *\left(\mathrm{~A}_{1 \mathrm{k}}^{\mathrm{s}}+\eta^{\mathrm{s}} A_{2 \mathrm{k}}^{\mathrm{s}}\right)\right] \\
& +i e_{s} \omega_{D}\left[\left(\Gamma_{\|}+\Gamma_{\perp}\right) / 2 \cdot \mathrm{U}_{\mathrm{k}}^{\mathrm{s}}-\mathrm{i} \sigma_{\mathrm{t}} \mu \mathrm{U}_{\mathrm{k}}^{\mathrm{s}}\right] \\
& \mathrm{dP}_{\mathrm{llk}}^{\mathrm{s}} / \mathrm{dt}=-\mathrm{i} \omega_{*}\left(1_{\mathrm{s}} \phi_{1 \mathrm{k}}^{\mathrm{s}}+\eta_{\mathrm{s}} \phi_{2 \mathrm{k}}^{\mathrm{s}}\right)+\mathrm{iX}{ }_{\| 1} \omega_{D} \phi_{12 \mathrm{k}}^{\mathrm{s}} \\
& -\mathrm{i} \tilde{k}_{\|}\left[\Gamma_{\|} \mathrm{U}_{\mathrm{k}}^{\mathrm{s}}-\mathrm{i} \sigma_{\mathrm{s}} \mathrm{M}_{\mathrm{s}}^{(-1 / 2)} \chi_{\mathrm{l}}^{\|} \mathrm{T}_{\| \mathrm{k}}^{\mathrm{s}}\right] \\
& +i e_{s} \omega_{D} \tau_{s}^{-1}\left[X_{\perp} P_{\| k}^{s}+(3 / 2) T_{\| k}^{s}+(1 / 2) T_{\perp k}^{s}-i \sigma_{t}\left(v_{\|\|}^{\| l} T_{\| k}^{s}+v_{\perp}^{\|} T_{\perp k}^{s}\right)\right] \\
& \mathrm{dP}_{\perp \mathrm{k}}^{\mathrm{s}} / \mathrm{dt}=-\mathrm{i} \omega_{*}\left[\left(1_{\mathrm{s}}-\eta_{\mathrm{s}}\right) \phi_{2 \mathrm{k}}+2 \eta_{\mathrm{s}} \phi_{3 \mathrm{k}}\right]+\mathrm{iX} \mathrm{L}_{\perp} \phi_{23 \mathrm{k}} \\
& -\mathrm{i} \tilde{k}_{\|}\left[\Gamma_{\perp} \mathrm{U}_{\mathrm{k}}-\mathrm{i} \sigma_{\mathrm{s}} \mathrm{M}_{\mathrm{s}}^{(-1 / 2)} \chi_{1}^{\perp} \mathrm{T}_{\perp \mathrm{k}}\right] \\
& +i e_{s} \omega_{D} \tau_{s}^{-1}\left[\mathrm{X}_{\perp} \mathrm{P}_{\perp k}^{\mathrm{s}}+\mathrm{T}_{\perp k}^{\mathrm{s}}+(1 / 2) \mathrm{T}_{\| k}^{\mathrm{s}}-\mathrm{i} \sigma_{\mathrm{t}}\left(v_{\|}^{\perp} \mathrm{T}_{\| k}^{\mathrm{s}}+v_{\perp}^{\perp} \mathrm{T}_{\perp \mathrm{k}}^{\mathrm{s}}\right)\right]
\end{aligned}
$$

and add the "magnetic flutter" nonlinearity to the $E \times B$ nonlinearity:

$$
\begin{aligned}
& \mathrm{i} \tilde{k}_{\|=} \mathrm{i} k_{\|}+\left(\beta_{\mathrm{e}} / 2\right) \sum_{\mathrm{k} 1}\left(\mathrm{k}_{\mathrm{x} 1} \mathrm{k}_{\mathrm{y} 2}-\mathrm{k}_{\mathrm{x} 2} \mathrm{k}_{\mathrm{y} 1}\right) \mathrm{A}_{\mathrm{k} 1} f_{\mathrm{k} 2} \\
& d f_{k} / d t=\partial f_{k} / \partial t+\Sigma_{\mathrm{k} 1}\left(k_{x 1} k_{\mathrm{y} 2} k_{x 2} k_{\mathrm{y} 1}\right) \phi_{k 1} f_{k 2}
\end{aligned}
$$


The cross field wave numbers are normed to the gyrorlength $\rho_{\mathrm{s}}=\mathrm{c}_{\mathrm{s}} / \Omega_{\mathrm{i}}$, and the parallel wave numbers and gradients to a, a typical minor radius of the plasma. The units for velocity and time are $c_{s}$ and $a / c_{s}$. The fields are normed to relative in gyrolength $\rho_{s} / a ;$ e.g. $\phi_{k}=\left(e / T_{e}\right) \Phi_{k} /\left(\rho_{s} / a\right) ;$ $\mathrm{A}_{\mathrm{k}}=\left(\mathrm{e} / \mathrm{T}_{\mathrm{e}}\right) A_{\| \mathrm{k}}\left(\mathrm{c}_{\mathrm{s}} / \mathrm{c}\right) /\left(\beta_{\mathrm{e}} / 2\right) /\left(\rho_{\mathrm{s}} / \mathrm{a}\right) . \quad \mathrm{M}_{\mathrm{s}}^{-1}=\mathrm{m}_{\mathrm{i}} / \mathrm{m}_{\mathrm{s}} ; \quad \tau_{\mathrm{s}}^{-1}=\mathrm{T}_{\mathrm{s}} / \mathrm{T}_{\mathrm{e}} ;$ and $\mathrm{e}_{\mathrm{S}}$ is the charge sign of species $s ; 1_{s}=a / L_{n}^{s} ; \eta_{s}=a / L_{T}^{s} ; \beta_{e}=n_{e} T_{e} /\left(B^{2} / 8 \pi\right)$. Quasi-neutrality and Ampere's law are given by

$$
\begin{aligned}
& \sum_{\mathrm{s}}\left(\mathrm{n}_{\mathrm{s}} / \mathrm{n}_{0}\right) \mathrm{e}_{\mathrm{s}} \mathrm{N}_{\mathrm{k}}^{\mathrm{s}}=\sum_{\mathrm{s}}\left(\mathrm{n}_{\mathrm{s}} / \mathrm{n}_{0}\right) \mathrm{e}_{\mathrm{s}}^{2} \tau_{\mathrm{s}}\left(\phi_{k}-\phi_{1 \mathrm{k}}^{\mathrm{s}}\right) \\
& \sum_{\mathrm{s}}\left(\mathrm{n}_{\mathrm{s}} / \mathrm{n}_{0}\right) \mathrm{e}_{\mathrm{s}} U_{\mathrm{k}}^{\mathrm{s}}=\mathrm{k}_{\perp}^{2} \mathrm{~A}_{\mathrm{k}}
\end{aligned}
$$

where $\mathrm{N}_{\mathrm{k}}^{\mathrm{s}}, \mathrm{U}_{\mathrm{k}}^{\mathrm{s}}, \mathrm{P}_{\mathrm{k}}^{\mathrm{s}}$ are the gyrocenter density, parallel velocity, and pressure perturbations with $T_{k}=P_{k}-N_{k}$. [] are higher moments closed by assuming a perturbed Maxwellian and the Maxwellian deviations are represented by the closer fit coefficients $\chi_{1}^{\prime \prime}=2 \chi_{1}^{\perp}=(\sqrt{2}) 2 / \sqrt{\pi}$ for parallel motion and $\mu=\left(0.80-0.57 \mathrm{i} \sigma_{\mathrm{t}}\right), v_{\|}^{\|}=v_{\perp}^{\perp}=\left(1-\mathrm{i} \sigma_{\mathrm{t}}\right), v_{\perp}^{\|}=v_{\|}^{\perp}=0$ for curvature motion (with $\left.\sigma_{\mathrm{s}}=\mathrm{k}_{\|} / \mathrm{k}_{\|} \mid, \sigma_{\mathrm{t}}=\omega_{\mathrm{D}} / \omega_{\mathrm{D}}\right)$ ). $\omega_{\mathrm{D}}$ is the curvature drift frequency and $\omega$ * is the drift frequency for electrons at unit density gradient length. The adiabatic compression indices are $\Gamma_{\|}=3, \Gamma_{\perp}=1, \mathrm{X}_{\|}=2, \mathrm{X}_{\perp}=3 / 2$

$$
\begin{aligned}
& \phi_{1 \mathrm{k}}=\Gamma_{0} \phi_{\mathrm{k}} \\
& \phi_{2 \mathrm{k}}=\left[\Gamma_{0}-\mathrm{b}\left(\Gamma_{0}-\Gamma_{1}\right)\right] \phi_{\mathrm{k}} \\
& \phi_{3 \mathrm{k}}=(1 / 2)\left[\left(2-4 \mathrm{~b}+\mathrm{b}^{2}\right) \Gamma_{0}-\left(5 \mathrm{~b} 2 \mathrm{~b}^{2}\right) \Gamma_{1}+\mathrm{b}^{2} \Gamma_{2}\right] \phi_{\mathrm{k}}
\end{aligned}
$$

with $\phi_{12 \mathrm{k}}=\left(\phi_{1 \mathrm{k}}+\phi_{2 \mathrm{k}}\right) / 2$ and $\phi_{23 \mathrm{k}}=\left(\phi_{2 \mathrm{k}}+\phi_{3 \mathrm{k}}\right) / 2$ represent the Bessel function gyroradius cut-offs and $b=\tau_{s}^{-1} M_{S}\left(k_{\perp} \rho_{s}\right)^{2}$. 
The $E \times B$ and magnetic flutter plasma and energy flows are respectively given by

$$
\begin{aligned}
& \Gamma_{\mathrm{x}}^{\mathrm{e}}=\mathrm{n}_{0} \mathrm{c}_{\mathrm{s}}\left(\rho_{\mathrm{s}} / \mathrm{a}\right)^{2}\left\langle\sum_{\mathrm{k}} \mathrm{N}_{\mathrm{k}}^{*}\left(-\mathrm{ik} \phi_{\mathrm{y}}\right)\right\rangle \\
& \mathrm{Q}_{\mathrm{sx}}^{\mathrm{e}}=\mathrm{p}_{0 \mathrm{~s}} \mathrm{c}_{\mathrm{s}}\left(\rho_{\mathrm{s}} / \mathrm{a}\right)^{2}(3 / 2)\left\langle\sum_{\mathrm{k}} \mathrm{P}_{\mathrm{k}}^{\mathrm{as} *}\left(-\mathrm{ik} \phi_{\mathrm{y}}\right)\right\rangle
\end{aligned}
$$

where $\mathrm{P}_{\mathrm{k}}^{\text {as }}=(1 / 3) \mathrm{P}_{\| \mathrm{k}}^{\mathrm{s}}+(2 / 3) \mathrm{P}_{\perp \mathrm{k}}^{\mathrm{s}} \cdot\langle\rangle$ represents a time average. Ampere's law forces electrons to flow with ions in magnetic flutter particle flow

$$
\begin{aligned}
& \Gamma_{\mathrm{x}}^{\mathrm{M}}=\mathrm{n}_{0} \mathrm{c}_{\mathrm{s}}\left(\rho_{\mathrm{s}} / \mathrm{a}\right)^{2}\left(\beta_{\mathrm{e}} / 2\right)\left\langle\sum_{\mathrm{k}} \mathrm{U}_{\mathrm{k}}^{\mathrm{i}^{*}}\left(-\mathrm{k}_{\mathrm{y}} \mathrm{A}_{\mathrm{k}}\right)\right\rangle \\
& \mathrm{Q}_{\mathrm{sx}}^{\mathrm{M}}=(3 / 2) \mathrm{T}_{0 \mathrm{~s}} \Gamma_{\mathrm{x}}^{\mathrm{M}}+\mathrm{n}_{0} \mathrm{c}_{\mathrm{s}}\left(\rho_{\mathrm{s}}{ }^{2} / \mathrm{a}\right) \chi^{\mathrm{M}}\left(-\partial T_{0 s} / \partial x\right)
\end{aligned}
$$

where in units of $c_{s}\left(\rho_{s}^{2} / a\right)$

$$
\begin{aligned}
\chi^{\mathrm{M}}= & \left(\beta_{\mathrm{e}} / 2\right) \sqrt{2}(2 / \sqrt{\pi}) / \sqrt{\mathrm{M}_{\mathrm{s}}} \\
& \times\left\langle\sum_{\mathrm{k}} \mid \mathrm{k}_{\|} \|^{-1}(\beta \mathrm{e} / 2) \mathrm{k}_{\mathrm{y}}^{2} \mathrm{~A}_{\mathrm{k}}^{*}\left\{\mathrm{~A}_{\mathrm{k}}-\mathrm{k}_{\|} \mathrm{T}_{\mathrm{sk}} /\left[\eta_{\mathrm{s}}\left(\beta_{\mathrm{e}} / 2\right) \mathrm{k}_{\mathrm{y}}\right]\right\}\right\rangle
\end{aligned}
$$

This essentially corresponds to magnetic flutter heat flow with the Hammett-Perkins parallel collisionless diffusivity $\chi_{\|}^{\mathrm{HP}}=(2 / \sqrt{\pi}) \mathrm{v}_{\mathrm{th}} / \mathrm{k}\|\|^{-1}$ in physical units. The first term represents Rechester-Rosenbluth field line diffusion and the second term is the Kadomtsev-Pogutse back reaction term which prevents significant magnetic heat flow as the field line becomes isothermal $\left\{A_{k}-k_{\|} T_{s k} /\left[\eta_{s}\left(\beta_{\mathrm{e}} / 2\right) k_{y}\right]\right\} \rightarrow 0$. It is unclear whether $\mid k_{k} \|^{-1}$ (which we interpret to be acting on $\mathrm{T}_{\mathrm{k}}$ ) really should be $\left|\tilde{k}_{\|}\right|^{-1}$ which is difficult to interpret. In any case we believe magnetic flutter flows will be very small. There is a turbulent energy exchange from electrons to ions given by

$$
\Delta=\mathrm{p}_{0} \mathrm{c}_{\mathrm{s}} / \mathrm{a}\left(\rho_{\mathrm{s}} / \mathrm{a}\right)^{2}\left\langle\Sigma_{k}\left(\partial N_{k}^{e} / \partial t\right) \phi_{\mathrm{k}}^{*}\right\rangle
$$


We model the trapping of electrons by dividing velocity space into a trapped region $\left(\left|v_{\|}\right|<\right.$ $\sqrt{\varepsilon} v)$ and untrapped regions $\left(\sqrt{\varepsilon} v<\left|v_{\|}\right|<v\right)$ and assuming $v_{\|} \approx 0$ in trapped region which has no response to $E_{\|} \cdot \sqrt{\varepsilon}=\{(r / R)[1+\cos (\theta)] /[1+(r / R) \cos (\theta)]\}^{1 / 2}$ is the local trapped fraction with $\theta$ the poloidal angle. The electron fluid is broken into trapped and untrapped fluids. The trapped electron fluid equations are closed to fit the trapped electron response function or energy integral in electrostatic limit

$$
N^{t} /(\sqrt{\varepsilon} \phi)=1-\int_{\text {trap }} d E F_{\max }\left[\omega-\omega *\left(1+\eta_{\mathrm{e}}(E-3 / 2)\right] /\left(\omega-\omega_{\mathrm{D}}^{*} \mathrm{E} / 2+\mathrm{i} v_{\mathrm{eff}} / \mathrm{E}^{3 / 2}\right)\right.
$$

where $F_{\max }=(2 / \sqrt{\pi}) \mathrm{E}^{1 / 2} \exp (-\mathrm{E}), v_{\mathrm{eff}}=\left\{v /[\sqrt{\varepsilon}(0)]^{2}\right\}(1-\sqrt{\varepsilon})$, and an integration is made over trapped portion of velocity space $\mathrm{v}_{\|}<\sqrt{\varepsilon} \mathrm{v}$. For the trapped electron fluid the closure gives

$$
\begin{aligned}
\mathrm{dN}_{\mathrm{k}}^{\mathrm{t}} / \mathrm{dt} & =-\mathrm{i} \omega_{*} 1_{e} \sqrt{\varepsilon} \phi_{\mathrm{k}}+\mathrm{i}(3 / 4) \omega_{\mathrm{D}} \sqrt{\varepsilon} \phi_{\mathrm{k}}-\mathrm{i} \omega_{\mathrm{D}}(3 / 4) \mathrm{P}_{\mathrm{k}}^{\mathrm{t}} \\
& -(\text { detrap }- \text { retrap })_{\mathrm{n}} \\
\mathrm{dP}_{\mathrm{k}}^{\mathrm{t}} / \mathrm{dt} & =-\mathrm{i} \omega_{*}\left(1_{\mathrm{e}}+\eta_{\mathrm{e}}\right) \sqrt{\varepsilon} \phi_{\mathrm{k}}+\mathrm{i} \omega_{\mathrm{D}}(5 / 4) \sqrt{\varepsilon} \phi_{\mathrm{k}}-\mathrm{i} \omega_{\mathrm{D}}\left[(5 / 4)+\zeta_{\mathrm{D}}\right]\left(\mathrm{P}_{\mathrm{k}}^{\mathrm{t}}-\mathrm{N}_{\mathrm{k}}^{\mathrm{t}}\right) \\
& -(\text { detrap }- \text { retrap })_{\mathrm{p}}
\end{aligned}
$$

where $N^{e}=N^{t}+N^{u}$ are the trapped and untrapped electron density, and $\zeta_{D}=-0.7+0.8 i . P_{k}^{t}$ is the trapped perpendicular pressure and the trapped parallel pressure is neglected. Since we have preserved the proportionality $\mathrm{Pt}^{\mathrm{t}}=(2 / 3)<\mathrm{E}>$ between pressure and energy, the energy transport is still given by adding the trapped pressure to the untrapped pressures. The trapped electrons carry no current so $U^{t}=0$. The collisional detrapping $\operatorname{model}^{7}$ is

$$
\begin{aligned}
& (\text { detrap - retrap })_{\mathrm{n}}=v /[\sqrt{\varepsilon}(0)]^{2}\left[(1-\sqrt{\varepsilon})\left(\mathrm{F}_{\mathrm{nn}} \mathrm{N}^{\mathrm{t}}+\mathrm{F}_{\mathrm{np}} \mathrm{P}^{\mathrm{t}}\right)-\sqrt{\varepsilon} \mathrm{F}_{\mathrm{nf}} \mathrm{N}^{\mathrm{u}}\right] \\
& (\text { detrap - retrap })_{\mathrm{p}}=v /[\sqrt{\varepsilon}(0)]^{2}\left[(1-\sqrt{\varepsilon})\left(\mathrm{F}_{\mathrm{pn}} \mathrm{N}^{\mathrm{t}}+\mathrm{F}_{\mathrm{pp}} \mathrm{P}^{\mathrm{t}}\right)-\sqrt{\varepsilon} \mathrm{F}_{\mathrm{pf}} \mathrm{N}^{\mathrm{u}}\right]
\end{aligned}
$$


where $v$ is the electron-ion collision frequency in units of $c_{\mathcal{S}} / a$. The energy bin fractions giving the same first and second moments as a Maxwellian are $\mathrm{t}_{\mathrm{h}}=4.08, \mathrm{t}_{\mathrm{c}}=0.918, \mathrm{f}_{\mathrm{h}}=0.184, \mathrm{f}_{\mathrm{c}}=$ 0.816 with $F_{n n}=\left[\left(t_{h} / t_{c}\right)^{3 / 2}-\left(t_{c} / t_{h}\right)^{3 / 2}\right] /\left[t_{h}-t_{c}\right], F_{n p}=(3 / 2)\left[\left(1 / t_{h}\right)^{3 / 2}-\left(1 / t_{c}\right)^{3 / 2}\right] /\left[t_{h}-t_{c}\right], F_{n f}=$ $\left(\mathrm{f}_{\mathrm{h}} / \mathrm{t}_{\mathrm{h}}\right)^{3 / 2}+\left(\mathrm{f}_{\mathrm{c}} / \mathrm{t}_{\mathrm{c}}\right)^{3 / 2}, \quad \mathrm{~F}_{\mathrm{p} \mathrm{n}}=(2 / 3)\left[\left(\mathrm{t}_{\mathrm{h}} / \mathrm{t}_{\mathrm{c}}\right)^{1 / 2}-\left(\mathrm{t}_{\mathrm{c}} / \mathrm{t}_{\mathrm{h}}\right)^{1 / 2}\right] /\left[\mathrm{t}_{\mathrm{h}}-\mathrm{t}_{\mathrm{c}}\right], \quad \mathrm{F}_{\mathrm{pp}}=\left[\left(1 / \mathrm{t}_{\mathrm{h}}\right)^{1 / 2}\right.$ $\left.\left(1 / t_{c}\right)^{1 / 2}\right] /\left[t_{h}-t_{c}\right]$, and $F_{p f}=(2 / 3)\left[\left(f_{h} / t_{h}\right)^{1 / 2}+\left(f_{c} / t_{c}\right)^{1 / 2}\right]$. Detailed balance and particle conservation are satisfied by the collision model and the trapped electron response becomes adiabatic (for passing electrons adiabatic) for $\mathbf{n}$ large.

For the untrapped electron fluid, we integrate over the untrapped portion of velocity space $\mathrm{v}>\mathrm{v} \|>\sqrt{\varepsilon} \mathrm{v}$

$$
\begin{aligned}
& \mathrm{dN}_{\mathrm{k}}^{\mathrm{u}} / \mathrm{dt}=-\mathrm{i} \omega_{*} 1_{e}(1-\sqrt{\varepsilon}) \phi_{\mathrm{k}}+\mathrm{i} \omega_{\mathrm{D}}[1-(3 / 4) \sqrt{\varepsilon}] \phi_{\mathrm{k}}-\mathrm{i} \tilde{k}_{\|} \mathrm{U}_{\mathrm{k}}^{\mathrm{u}} \\
& -\mathrm{i} \omega_{D} \tau_{\mathrm{e}}^{-1}\left(\mathrm{P}_{\| \mathrm{k}}^{\mathrm{u}}+\mathrm{P}_{\perp \mathrm{k}}^{\mathrm{u}}\right) / 2+(\text { detrap - retrap })_{\mathrm{n}} \\
& \mathrm{dU}_{\mathrm{k}}^{\mathrm{u}} / \mathrm{dt}=-\mathrm{i} \tilde{k}_{\|} \mathrm{M}_{\mathrm{e}}^{-1}\left(\tau_{\mathrm{e}}^{-1} \mathrm{P}_{\mathrm{lk}}^{\mathrm{u}}-\phi_{\mathrm{k}}\right) \\
& -\mathrm{M}_{\mathrm{e}}^{-1}\left(\beta_{\mathrm{e}} / 2\right)\left[-\partial \mathrm{A}_{\mathrm{k}} / \partial \mathrm{t}-\mathrm{i} \omega_{*}\left(1+\eta^{\mathrm{e}}\right) A_{\mathrm{k}}\right] \\
& -i \omega_{D}\left[\left(\Gamma_{\|}+\Gamma_{\perp}\right) / 2 \cdot \mathrm{U}_{\mathrm{k}}^{\mathrm{u}}-\mathrm{i} \sigma_{\mathrm{t}} \mu \mathrm{U}_{\mathrm{k}}^{\mathrm{u}}\right] \\
& \mathrm{dP}_{\| \mathrm{k}}^{\mathrm{u}} / \mathrm{dt}=-\mathrm{i} \omega_{*}\left(1_{\mathrm{e}}+\eta_{\mathrm{e}}\right) \phi_{\mathrm{k}}+\mathrm{iX} \mathrm{X}_{\|} \omega_{D} \phi_{\mathrm{k}} \\
& -\mathrm{i} \tilde{k}_{\|}\left[\Gamma_{\|} \mathrm{U}_{\mathrm{k}}^{\mathrm{u}}-\mathrm{i} \sigma_{\mathrm{s}} \mathrm{M}_{\mathrm{e}}^{(-1 / 2)} \chi_{1}^{\|}\left[(1-\sqrt{\varepsilon}) \mathrm{P}_{\| \mathrm{k}}^{\mathrm{u}}-\mathrm{N}_{\mathrm{k}}^{\mathrm{u}}\right]\right] \\
& -i \omega_{D} \tau_{s}^{-1}\left[X_{\|} P_{\| k}^{u}+(3 / 2) T_{\| k}^{u}+(1 / 2) T_{\perp k}^{u}-i \sigma_{t}\left(v_{\|\|}^{\|} T_{\| k}^{u}+v_{\perp}^{\|} T_{\perp k}^{u}\right)\right] \\
& \mathrm{dP}_{\perp \mathrm{k}}^{\mathrm{u}} / \mathrm{dt}=-\mathrm{i} \omega_{*}\left(1_{\mathrm{e}}+\eta_{\mathrm{e}}\right)[1-(3 / 2) \sqrt{\varepsilon}] \phi_{\mathrm{k}}+\mathrm{iX} \mathrm{X}_{\perp} \omega_{D}\left[\mathrm{x}_{\perp}-(15 / 8) \sqrt{\varepsilon}\right] \phi_{\mathrm{k}} \\
& -\mathrm{i} \tilde{k}_{\|}\left[\Gamma_{\perp} \mathrm{U}_{\mathrm{k}}^{\mathrm{u}}-\mathrm{i} \sigma_{\mathrm{s}} \mathrm{M}_{\mathrm{e}}^{(-1 / 2)} \chi_{1}^{\|}\left[(1-\sqrt{\varepsilon}) \mathrm{P}_{\| \mathrm{k}}^{\mathrm{u}}-\mathrm{N}_{\mathrm{k}}^{\mathrm{u}}\right]\right] \\
& -i \omega_{\mathrm{D}} \tau_{\mathrm{e}}^{-1}\left[\mathrm{X}_{\perp} \mathrm{P}_{\perp \mathrm{k}}^{\mathrm{u}}+\mathrm{T}_{\perp \mathrm{k}}^{\mathrm{u}}+(1 / 2) \mathrm{T}_{\| \mathrm{k}}^{\mathrm{u}}-\mathrm{i} \sigma_{\mathrm{t}}\left(v_{\|}^{\perp} \mathrm{T}_{\| \mathrm{k}}^{\mathrm{u}}+v_{\perp}^{\perp} \mathrm{T}_{\perp \mathrm{k}}^{\mathrm{u}}\right)\right]
\end{aligned}
$$


The adiabatic untrapped electron response is obtained for $\mathrm{k}_{\|} \rightarrow \infty$ by the $\chi_{1}^{\|}$term forcing (1$\sqrt{\varepsilon}) \mathrm{P}_{\| \mathrm{k}}^{\mathrm{u}} \rightarrow \mathrm{N}_{\mathrm{k}}^{\mathrm{u}}$ and ohm's law forcing $\mathrm{P}_{\| \mathrm{k}}^{\mathrm{u}} \rightarrow \phi_{\mathrm{k}}$ so that $\mathrm{N}_{\mathrm{k}}^{\mathrm{u}} \rightarrow(1-\sqrt{\varepsilon}) \phi_{\mathrm{k}}$. However the $(1-\sqrt{\varepsilon}) P_{\| k}^{u}$ term required to get the adiabatic limit is difficult to handle numerically. Thus we replace $(1-\sqrt{\varepsilon}) \mathrm{P}_{\| \mathrm{k}}^{\mathrm{u}}-\mathrm{N}_{\mathrm{k}}^{\mathrm{u}}$ with $\mathrm{P}_{\| \mathrm{k}}^{\mathrm{u}}-\mathrm{N}_{\mathrm{k}}^{\mathrm{u}}$ in the $P_{\| k}^{u}$ equation and insert $(1-\sqrt{\varepsilon})$ factors in front of the $\phi_{\mathrm{k}}$ and $\mathrm{A}_{\mathrm{k}}$ terms in Ohm's law $\mathrm{U}_{\mathrm{k}}^{\mathrm{u}}$ equation. Thus apart from the electric and magnetic potential terms reflecting a reduced portion of velocity space, the fluid closure is the same as the purely passing electron model closure given above. Unfortunately this closure has the feature that the non adiabatic or Landau resonance portion of the electron response at small $\lambda$ $=\left(\omega / \mathrm{k}_{\|} \nu_{\mathrm{th}}^{\mathrm{e}}\right)$ falls off incorrectly as $\lambda^{1}$ instead of $\lambda^{3}$ required by the subtracted $\mathrm{Z}$ functions response for untrapped electrons:

$$
\mathrm{N}_{\mathrm{k}}^{\mathrm{u}} /(1-\sqrt{\varepsilon}) \phi_{\mathrm{k}}=\left\{1+[Z((\lambda)-Z(\lambda / \sqrt{\varepsilon}) /(1-\sqrt{\varepsilon})]\} \rightarrow 1+\mathrm{i} \pi^{1 / 2} \lambda^{3}(1+\sqrt{\varepsilon}) / \varepsilon\right.
$$

in the electrostatic limit without curvature. Thus the Landau resonance of the untrapped electrons is over weighted. There appears to be no way to avoid this without going to higher moments in the closure.

It is straightforward to show that combining the purely passing ion fluid with the trapped and untrapped fluids, that the one fluid incompressible ideal MHD high-n ballooning mode equations are obtained in the $\mathrm{k}_{\perp} \rightarrow 0$ limit provided the compression terms proportional to $i \omega_{\mathrm{D}} \phi_{\mathrm{K}}$ and $\mathrm{i} \mathrm{k}_{\|} \Gamma_{\mathrm{k}}^{\mathrm{u}}$ are explicitly dropped. However under the assumption that the pressure perturbations are close to isotropic, compression will not change the critical MHD beta.

\section{B. Nonlinear ballooning mode representation}

Reference 2 gives a complete formulation and discussion of the nonlinear ballooning mode representation (BMR) and numerical methods. Here for convenience and completeness we note 
that the BMR is a cross field Fourier transform of the field line following "twisted eddy" basis 8 $\left(k_{x}^{\prime}, k_{y}^{\prime}, z^{\prime}\right)$ where $k_{x}=k_{x}^{\prime}+\hat{s}\left(z^{\prime} / R q\right) k_{y}^{\prime}$ with shear $\hat{s}=d \operatorname{lnq} / d \ln r$, the ballooning mode angle $\hat{\theta}$ $=-\mathrm{k}_{\mathrm{x}}^{\prime} /\left(\hat{\mathrm{s}} \mathrm{k}_{\mathrm{y}}^{\prime}\right), \mathrm{k}_{\mathrm{y}}=\mathrm{k}_{\mathrm{y}}^{\prime}=(\mathrm{nq} / \mathrm{r})$ refers to the toroidal mode number $\mathrm{n} . \mathrm{z}^{\prime}=\mathrm{Rq} \theta$ is the distance along the field is related to the extended poloidal angle $\theta$ and $\mathrm{ik}_{\|}=\partial / \partial \mathrm{z}^{\prime}=(1 / \mathrm{Rq}) \partial / \partial \theta$. Thus $(\hat{\theta}, \mathrm{n}, \theta)$ or $\left(\mathrm{k}_{\mathrm{x}}^{\prime}, \mathrm{k}_{\mathrm{y}}^{\prime}, \mathrm{z}^{\prime}\right)$ are interchangeable labels for the perturbed fields. The finite-n fields $\mathrm{F}$ are made periodic in the physical poloidal angle by including p labeled "image modes" in phase with $\mathrm{p}=0$ "primary" modes $\mathrm{F}_{\mathrm{n}}^{\hat{\theta}}+2 \pi \mathrm{p}(0)=\exp (-\mathrm{ip} 2 \pi \mathrm{nq}) \mathrm{F}_{\mathrm{n}}^{\hat{\theta}}(\theta-2 \pi \mathrm{p})$ The $\mathrm{n}=0\left(\mathrm{k}_{\mathrm{y}}^{\prime}=0\right.$ but finite $\left.\mathrm{k}_{\mathrm{x}}^{\prime}\right)$ "radial" modes are naturally $2 \pi$ periodic. For a sheared magnetic field we must also replace $k_{\|}$ with $\mathrm{k}_{\mathrm{l}}-\mathrm{i}(\hat{\mathrm{s}} / \mathrm{Rq})\left(\mathrm{k}_{\mathrm{y}} \mathrm{k}_{\mathrm{x}} / \mathrm{k}_{\perp}^{2}\right) \mathrm{b} \Gamma_{0}^{\prime}(\mathrm{b}) / \Gamma_{0}(\mathrm{~b})$. In this notation the curvature drifts become $\omega_{\mathrm{D}}=$ $(2 \mathrm{a} / \mathrm{R}) \omega *\left[\cos (\theta)-\mathrm{x}_{\mathrm{mw}}+[\hat{\mathrm{s}} \theta-\hat{\mathrm{s}} \hat{\theta}-\alpha \sin (\theta)] \sin (\theta)\right]$ for the $\hat{\mathrm{s}}-\alpha$ shifted circle equilibrium. Here $\mathrm{x}_{\mathrm{mw}}$ represents the possibility of a magnetic well or average favorable curvature. Treatment of real geometry along the field line in magnetic angle coordinates is in fact quite straightforward for the nonlinear BMR; this is formulated in Waltz and Boozer ${ }^{9}$ for stellarator geometry but applies equally well to general tokamak geometry.

\section{Special numerical methods for simulation of electron models}

There are two critical numerical difficulties in treating untrapped (or passing) electrons. The equations are stiff in time in the sense that the speed of the waves which we want to follow are much slower that the electron transit along the field line (i.e. there is a very large coefficient in the equations $\mathrm{M}_{\mathrm{e}}^{-1 / 2}$ ). In the ballooning mode representation we represent the distance along the field line by the extended poloidal angle $\theta(z=R q \theta)$. The equations are also stiff in space in the sense that the fluid electron dynamics (or Landau resonance point) is confined to a very narrow region near the singular surface where $k_{\|}=(\mathrm{i} / \mathrm{Rq}) \partial / \partial \theta$ is small. This corresponds to a long slow interchange like component to the ballooning modes in $\theta$-space. 
To handle the time stiffness we use a small storage implicit "response matrix" method developed by Kotschenreuther ${ }^{6}$ for a gyrokinetic ballooning mode gyrokinetic code. Rather than advance some 300 or more components of energy-pitch angle space per species we advance 4 moments. Only terms involving $k_{\|}$and the inductive term $\left[-\partial A_{k} / \partial t-i \omega *\left(1+\eta^{e}\right) A_{k}\right]$ need be handled implicitly. The drift terms as well as the collisional and nonlinear terms are slow enough to be done explicitly. Unlike Ref. 6 which is done exclusively in $\theta$-space, the time advance for the fluid moments is done in $k_{\|}$or $\theta$-transform space whereas only the quasi-neutrality/Ampere's law and the compensating response matrix calculation to update the potentials is done in $\theta$-space. The moments are first updated with zero potentials, then the advanced potentials are calculated with quasi-neutrality/Ampere's law and the response matrix compensating for use of moments advanced with zero potentials, then the moments are finally updated with the advanced potentials.

The space stiffness is best understood in terms of the Nyquist relation for grids: the grid spacing is $\Delta \mathrm{k}_{\|}=\pi /\left(\mathrm{Rq} \theta_{\max }\right)$. If we resolve the electron Landau layer inside $\mathrm{k}_{\| \mathrm{r} e \mathrm{~s}}=\omega / \mathrm{v}_{\text {the }}$, we are forced to have large $\theta_{\max }$. If we use a reasonably small $\theta_{\max }(\mathrm{a}$ few $\pi$ 's) the fluid electron layer represented by the $\mathrm{k}_{\|}=0$ grid point is "over weighted" in the sense that it assigns "fluid" limit electron dynamics $k_{\|} \ll<k_{\| r e s}$ to too large a portion $k_{\|}$-space and the overall untrapped electron response is far from adiabatic [i.e. $\mathrm{Nu}_{\mathrm{k}}$ is not near $(1-\sqrt{\varepsilon}) \phi_{\mathrm{k}}$ ]. To avoid this we use "sine-cosine" transforms with zero boundary conditions at $\theta_{\max }$ for "sin-fields" $\phi_{k}, \mathrm{~N}_{\mathrm{k}}, \mathrm{Pu}_{\mathrm{k}}$ and zero gradient boundary conditions for the "cos-field" $U_{k}$ (rather than cyclic boundary conditions imposed by standard Fourier transforms). This forces the $k_{\|}=0$ component to be zero. The end result is that the ballooning mode growth rates are independent of $\theta_{\max }$ at much lower values of $\theta_{\max }$ than obtained with cyclic boundary conditions. Independence of boundary condition is the final test of validity and we are able to work sensibly down to $\theta_{\max }=3 \pi$ when $\sqrt{\varepsilon(0)}$ is large enough to have a significant trapped electron response. However at very small $\sqrt{\varepsilon(0)}$ where the passing electrons dominate, $\theta_{\max }$ beyond $10 \pi$ may be required. 
The response function technique 6 is a relatively low storage method in which the field storage (and computational time) scale as $\mathrm{k} \mathrm{j}$ where $\mathrm{j}$ is the number of $\theta$ grids and $\mathrm{k}$ is the number of $\left(\mathrm{k}_{\mathrm{X}}, \mathrm{k}_{\mathrm{y}}\right)$ modes plus the storage of the response matrix scaling as $\mathrm{k} \mathbf{x}$ $(2 \mathrm{j})^{2}$. The latter storage however is not insignificant. We believe that a completely general implicit Kyrlov method ${ }^{10}$ which requires only field storage will untimately prove to be the most practical.

\section{Rotational shear stabilization and rotational momentum transport}

Profile effects or gradual inhomogeneities are generally $\rho_{\mathrm{s}} / \mathrm{a}$ small and ignorable. The exceptions are when the plasma is spun up to have large equilibrium potentials with $e \Phi / T_{e} \gg 1$ or when sharp gradients of in the radial electric field build up near the plasma edge as it balances the diamagnetic rotation. In either case the sheared flow $\mathrm{cE}_{\mathrm{x}}^{\prime} / \mathrm{B}$ rate can be comparable to the mode growth rate $\gamma\left(k_{x} / k_{y}\right)$. Homogeneity is broken. This can be accounted for within the BMR by including a linear coupling between the $k_{x}^{\prime}$ modes

$$
\partial \mathrm{f}_{\mathrm{k}} / \partial \mathrm{t} \rightarrow \partial \mathrm{f}_{\mathrm{k}} / \partial \mathrm{t}+\gamma_{\mathrm{E}} \mathrm{k}_{\mathrm{y}}^{\prime} \partial \mathrm{f}_{\mathrm{k}} / \partial \mathrm{k}_{\mathrm{x}}^{\prime}
$$

where $\gamma_{\mathrm{E}}$ is the total Doppler shear rate. In general it is given by

$$
\gamma_{E}=\left[r \partial\left(V_{E} / r\right) / \partial r-V_{\|} /(R q / \hat{s})\right] /\left(c_{s} / a\right)
$$

where $\mathrm{V}_{\mathrm{E}}$ is the equilibrium $E \times B$ velocity and $\mathrm{V}_{\|}$the parallel velocity. in effect $\mathrm{x}=\hat{\mathrm{x}}$ is replace by $-\mathrm{i} \partial / \partial \mathrm{k}_{\mathrm{x}}^{\prime}$. When evaluated in $\mathrm{x}$-space this represents a linear variation in flow velocity across the "simulation box" but when evaluated in $\mathrm{k}_{\mathrm{X}}$-space one must be careful to use a harmonic derivative. ${ }^{2}$ Shear in the parallel velocity drives a Kelvin-Helmholtz like instability. A term $-\mathrm{i} \gamma \mathrm{pk}_{\mathrm{y}}^{\prime} \phi_{\mathrm{k}}$ must be added to the right hand side of the parallel ion motion $\left(\mathrm{U}_{\mathrm{k}}\right)$ equation where 
$\gamma_{\mathrm{P}}=\mathrm{V}_{\mathrm{H}}^{\prime} /\left(\mathrm{c}_{\mathrm{s}} / \mathrm{a}\right)$. For purely toroidal rotation typical of tokamak cores $\gamma_{\mathrm{E}}=(\mathrm{r} / \mathrm{q})$ $[\partial(\mathrm{V} \phi / \mathrm{R}) / \partial \mathrm{r}] /\left(\mathrm{c}_{\mathrm{s}} / \mathrm{a}\right)$ which is not quite the same as the shear in the $E \times B$ velocity $\partial\left(\mathrm{r} \mathrm{V}_{\phi} / \mathrm{qR}\right) / \partial \mathrm{r}=$ $c E_{x}^{\prime} / B$. Furthermore $\gamma_{P}=\partial\left(V_{\phi} / \partial r\right) /\left(c_{s} / a\right)$ so $\gamma_{P}=(R q / r) \gamma_{E}$

Rotational shear stabilizes the turbulence and not only reduces heat and particle transport but also the transport of rotational momentum. The toroidal ion momentum balance equation discounting the momentum source is

$$
\mathrm{M} \partial \Gamma_{\phi} / \partial \mathrm{t}+\partial \Pi_{\phi \mathrm{x}} / \partial x=0
$$

We define the toroidal viscosity $\eta_{\phi x}$ by $\Pi_{\phi x}=M n_{0} \eta_{\phi x}(-\partial V \phi / \partial x)$. (The electron momentum can be neglected.) The projection of the parallel $\Pi_{\| x}$ and perpendicular $\Pi_{\perp x}$ stress tensors into the toroidal direction gives $\Pi_{\phi x} \approx \Pi_{\| x}+\left(\mathrm{B}_{\theta} / \mathrm{B}_{\phi}\right) \Pi_{\perp \mathrm{x}}$ with $\left(\mathrm{B}_{\theta} / \mathrm{B}_{\phi}\right)=\mathrm{r} / \mathrm{Rq}$. For $\Pi_{\phi x}, \Pi_{\| x}$, and $\Pi_{\perp x}$ in units of $n_{0} T_{0}\left(\rho_{s} / a\right)^{2}$, the toroidal viscosity $\eta_{\phi_{x}}$ in diffusion units $c_{s} \rho_{s}^{2} / a$, and the toroidal rotational shear $\gamma_{\mathrm{P}}=(-\partial \mathrm{V} \phi / \partial \mathrm{x})$ in units of $c_{\mathrm{S}} / \mathrm{a}$ we can write $\Pi_{\phi x}=\eta_{\phi x} \not \mathrm{p}$. In terms of the normalized field fluctuations

$$
\begin{aligned}
& \Pi_{\mathrm{llx}}=\left\langle\Sigma_{\mathrm{k}}\left(-\mathrm{i} \mathrm{k}_{\mathrm{y}} \phi_{\mathrm{k}}\right)^{*} \mathrm{U}_{\mathrm{k}}\right\rangle \\
& \Pi_{\perp \mathrm{x}}=\left\langle\Sigma_{\mathrm{k}}\left(-\mathrm{k}_{\mathrm{y}} \mathrm{k}_{\mathrm{x}} \phi_{\mathrm{k}}\right)^{*}\left[\phi_{\mathrm{k}}+\left(\mathrm{T}_{\mathrm{i}} / \mathrm{T}_{\mathrm{e}}\right) \mathrm{P}_{\mathrm{k}}\right]\right\rangle
\end{aligned}
$$

where the first term is $E \times B$ and the second is diamagnetic flow. [It should be noted that the relative sign between $\gamma_{\mathrm{E}}$ and $\gamma_{\mathrm{P}}$ must be tested to insure pure toroidal motion and sign between the $\Pi_{\| x}$ and $\Pi_{\perp x}$ terms, i.e. the sign of $\left(B_{\theta} / B_{\phi}\right)$, can be checked to insure pure cross field viscosity is positive in the large $\left(\mathrm{B}_{\theta} / \mathrm{B}_{\phi}\right)$ limit.] 


\section{TOROIDAL ITG TURBULENCE WITH ADIABATIC ELECTRONS}

Unless otherwise stated, the numerical illustrations here and below have standard case parameters $\mathrm{q}=2, \hat{\mathrm{s}}=1, \mathrm{a} / \mathrm{L}_{\mathrm{n}}=1, \mathrm{a} / \mathrm{L}_{\mathrm{T}}=3, \mathrm{a} / \mathrm{R}=1 / 3, \tau^{-1}=\mathrm{T}_{\mathrm{i}} / \mathrm{T}_{\mathrm{e}}=1$. Similarly the local shear, magnetic well, beta, and collision frequency are nil $\left(\alpha=0, x_{m w}=0, \beta_{e}=0, v=0\right)$ and where relevant for trapped electrons $r / R=1 / 6$. The $\left(k_{y}^{\prime}, k_{x}^{\prime}\right)$ grid spanning $0<k_{y}^{\prime}<1$ has a 10 x 40 quadrant with $40 \mathrm{k}_{\mathrm{y}}^{\prime}=0$ radial modes for a total of 850 complex ballooning mode amplitudes. $\hat{\theta}_{\max }=\pi$ implies $\mathrm{k}_{\mathrm{x}_{\max }^{\prime}}=\hat{\mathrm{s}} \pi$. This corresponds to a cross field box with $\Delta \mathrm{x}^{\prime}=\Delta \mathrm{y}^{\prime}(4 / \hat{\mathrm{s}} \pi)=80 \rho_{\mathrm{s}}$. Along the field line, 64 grids span $-2 \pi<\theta<2 \pi$ with sufficient image modes $^{2}$ (having $\hat{\theta}>\pi$ or $\hat{\theta}<-\pi$ ) to make the net amplitudes and diffusion $2 \pi$ periodic. For the adiabatic electrons model treated in this section $N_{k}^{e}=\left(\phi_{k}-\langle\phi\rangle_{k}\right)$ where the average potential along the field line $\langle\phi\rangle_{k}$ is 0 for finiten (finite $k_{y}^{\prime}$ ) ballooning modes but is not zero for the $n=0$ radial modes. From Ref. 2 the standard case diffusion has a flux surface average $\chi_{\mathrm{i}}=1.9 \mathrm{c}_{\mathrm{s}} \rho_{\mathrm{s}}^{2} / \mathrm{a}$ (with $8: 1$ out/in asymmetry) which about 3 times $\mathrm{D}_{\mathrm{ML}} ;\left(\tilde{p^{a} / p_{0}}\right) \rho_{\mathrm{S}} / \mathrm{a}$ (with $2: 1$ out/in asymmetry); and $\left(|\tilde{n}| / \mathrm{n}_{0}\right)(\boldsymbol{\theta}=0)=6.5 \rho_{\mathrm{S}}$ a. The peak diffusion and turbulence level is at $\mathrm{k}_{\mathrm{y}}^{\prime}=0.2$ down shifted from the location of peak growth at $\mathrm{k}_{\mathrm{y}}^{\prime}=0.3$

\section{A. Long radial wavelength structure and short correlation lengths}

There are several ways to represent the nonlinear turbulent state. For example Ref. 2 shows an instantaneous color contour plot of the density fluctuations projected into real space as annulus at fixed toroidal $(\phi=0)$ angle spanning $-\pi<\theta<\pi$ in Fig. 5; and a contour and slice summation plot of the time average $\left(\mathrm{k}_{\mathrm{x}}^{\prime}, \mathrm{k}_{\mathrm{y}}^{\prime}\right)$ density spectrum $\left\langle\left|\tilde{n}\left(\mathrm{k}_{\mathrm{x}}^{\prime}, \mathrm{k}_{\mathrm{y}}^{\prime}\right) / n_{0}\right|\right\rangle_{\mathrm{rms}}$ at $\phi=0, \theta=0$ in Fig. 6 . However there appears at first to be a curious inconsistency between the instantaneous real space plot and the time average k-space spectrum. The Ref. 2 Fig. 5 contour plot clearly shows eddies which are highly elongated in the radial direction being as much as $40 \rho_{\mathrm{s}}$ in radial half width but only about $5 \rho_{\mathrm{s}}$ in poloidal halfwidth. Afull radial width of $80 \rho_{\mathrm{s}}$ could be in some cases a 
sizable fraction of a typical tokamak radius. (In this illustration the annulus is $\Delta x=160 \rho_{\mathrm{s}}$ wide since it was done with a $10 \mathrm{k}_{\mathrm{y}}^{\prime} \times 80 \mathrm{k}_{\mathrm{x}}^{\prime}$ quadrant grid and hence twice as wide as the standard case). In contrast the if we represent the time average spectral function $\left\langle\left|\tilde{n}\left(\mathrm{k}_{\mathrm{x}}^{\prime}, \mathrm{k}_{\mathrm{y}}^{\prime}\right) / n_{0}\right|\right\rangle^{2}$ rms as a Gaussian $\exp \left\{-\left[\left(\mathrm{k}_{\mathrm{y}}^{\prime}-\mathrm{k}_{\mathrm{y} 0}\right) /\left(2^{1 / 2} \delta \mathrm{k}_{\mathrm{y}}\right)\right]^{2}-\left[\mathrm{k}_{\mathrm{x}}^{\prime} /\left(2^{1 / 2} \delta \mathrm{k}_{\mathrm{x}}\right)\right]^{2}\right\}$ then the correlation function in real space $\left\{\tilde{n}\left(x^{\prime}, y^{\prime}\right) \tilde{n}(0,0)\right\rangle /\left.\right|_{-2}\langle\tilde{n}(0,0) \tilde{n}(0,0)\rangle$ will be c o s $\left[(\pi / 2)\left(\mathrm{y}^{\prime} / \mathrm{y}_{0}\right)\right]$ $\exp \left\{-\left[\mathrm{y}^{\prime} /\left(2^{1 / 2} \delta \mathrm{y}\right)\right]^{2}-\left[\mathrm{x}^{\prime} /\left(2^{1 / 2} \delta \mathrm{x}\right)\right]^{2}\right\}$ with $\delta \mathrm{x}=1 / \delta \mathrm{k}_{\mathrm{x}}, \delta \mathrm{y}=1 / \delta \mathrm{k}_{\mathrm{y}}$, and $\mathrm{y} 0=(\pi / 2) / \mathrm{k}_{\mathrm{y} 0}$. [Note for a Gaussian $\delta \mathrm{x}$ is related to the rms $\delta \mathrm{x}$ and the "half width at half $\max$ " by $\delta \mathrm{x}=\delta \mathrm{x}_{\mathrm{rms}}=$ $\mathrm{x}_{\mathrm{hwhm}}$ /1.177]. From Fig 6. of Ref 2. $\delta \mathrm{k}_{\mathrm{x}} \approx \delta \mathrm{k}_{\mathrm{y}} \approx 0.1$ (using the 70\% point of $\left.\left\langle\left|\tilde{n}\left(\mathrm{k}_{\mathrm{x}}^{\prime}, \mathrm{k}_{\mathrm{y}}^{\prime}\right) / n_{0}\right|\right\rangle_{\mathrm{rms}}\right)$, and $\mathrm{k}_{\mathrm{y} 0}=0.2$, from which we can infer $\mathrm{x}_{\mathrm{hwhm}}=14 \rho_{\mathrm{s}}, \mathrm{y}_{\mathrm{hwhm}}=14 \rho_{\mathrm{s}}$, and y0 $=8 \rho_{\mathrm{s}}$. These characteristics are consistent with experimental observations ${ }^{11}$ of time average correlation functions. The real space time average radial correlation function $I(x, 0)$ is shown in Figure 1(a), the poloidal or vertical correlation function $I(0, y)$ in Figure 1(b) with averages over time of 300 and $600 \mathrm{a} / \mathrm{c}_{\mathrm{s}}$. ( The $14 \rho_{\mathrm{s}}$ half width at half max suggested by Gaussian spectral functions are shown by I-bars.) [We define the correlation functions with time averages $<>$ by $\left.I(x, y)=<\tilde{n}(x, y) \tilde{n}(0,0)>/[<\tilde{n}(x, y) \tilde{n}(x, y)><\tilde{n}(0,0) \tilde{n}(0,0)>]^{1 / 2}\right]$. The radial correlation functions are in fact rather slow to form on the time scale of the simulations and a long radial correlation component takes some time to die out. The experimental correlation functions are taken over much longer times than shown here. It is clear however that time average correlation lengths are longer than than eddy widths in the poloidal direction and considerably shorter than eddy widths in the radial direction. The elongated eddies are intermittent and essentially short lived. Thus we can not infer from experimental short radial correlation lengths that long wave structure do not exist, at least over short times. 

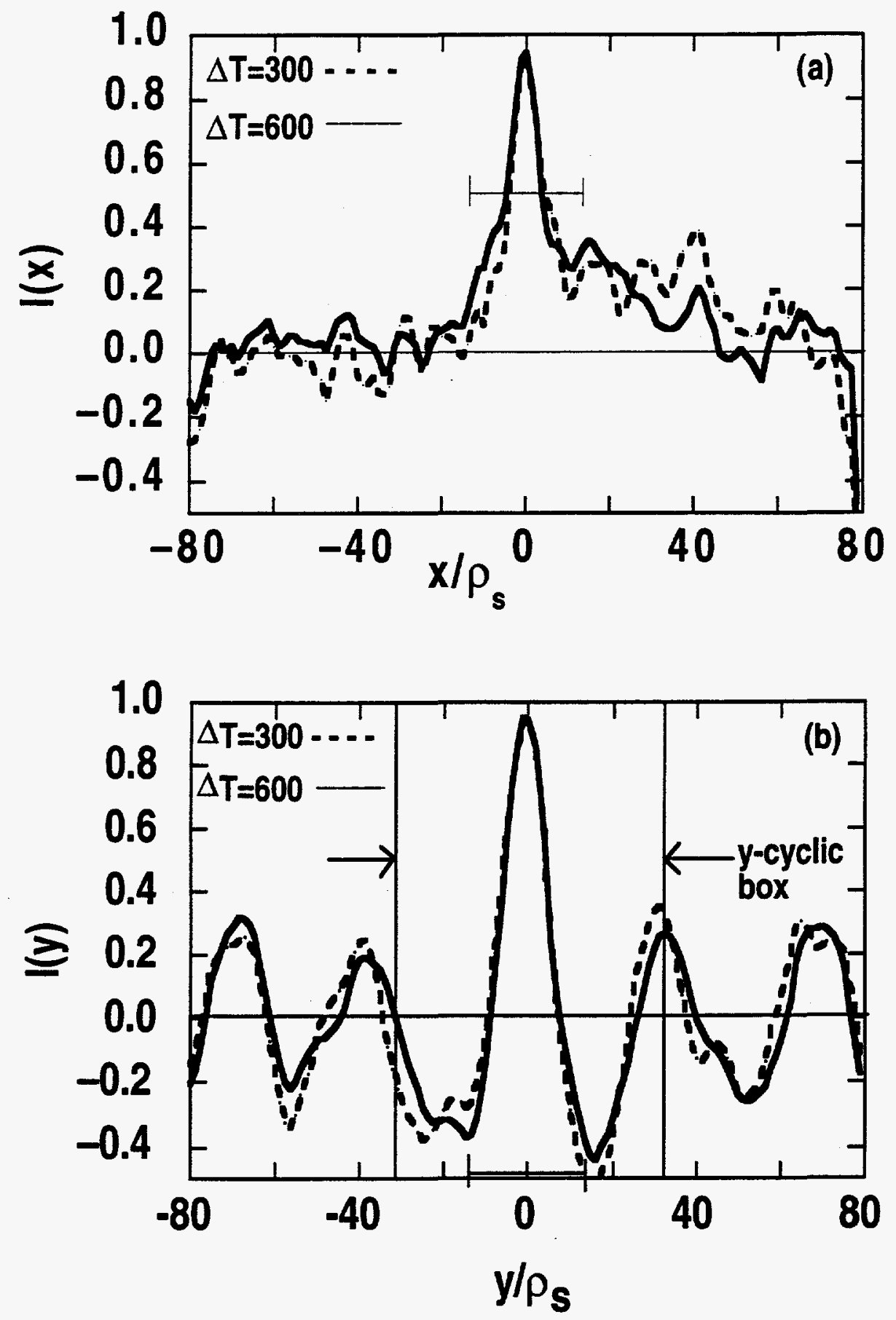

Fig. 1. Radial (a) and poliodal (b) correlation functions at various time averaging intervals. 


\section{B. Transport a reverse global shear, with local shear, and average favorable curvature}

Previous work ${ }^{2,3}$ has explored the behavior with $\mathrm{q}$, positive global shear $\hat{s}$, with temperature gradients, and also in $\mathrm{T}_{\mathrm{i}} / \mathrm{T}_{\mathrm{e}}$ ratio. ${ }^{3}$ Here we fill out some of this parametric dependence on reverse global shear $(\hat{s}<0)$, local shear $(\alpha)$, and average favorable curvature or magnetic well $\left(\mathrm{x}_{\mathrm{mw}}\right)$. Shear reversal causes the geodesic curvature ( $\sin \theta$ term) to work against rather than with the normal curvature $(\cos \theta$ term). Thus it is not surprising that the driving rates and the resulting transport decrease. Figure 2 show a full range of normal and reverse shear. For example $\hat{s}=-0.5$ to -1.0 has almost four-fold less transport than $\hat{s}=0.5$ to 1.0 and transport is not particularly large at vanishing shear.

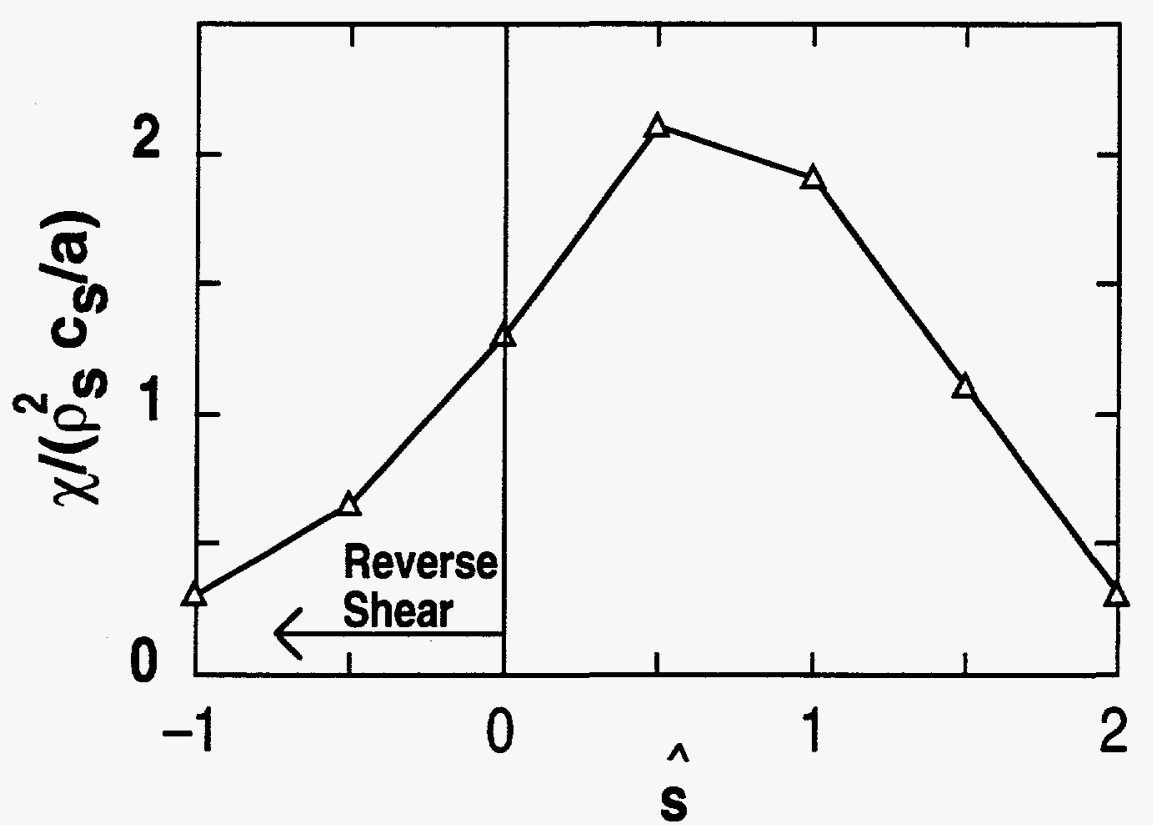

Fig. 2. Diffusion at both positive and negative shear.

At moderate global shear $(\hat{s}=1)$ the local shear acts to decrease the effective shear ( $\mathrm{s} \theta-$ $\alpha \sin \theta)$ near $\theta=0$ where the modes live; thus we expect that driving rates to increase. Just as in the case of the $s-\alpha$ model for ideal MHD where the critical beta (critical $\alpha$ ) boundary is split to a lower first stable boundary and a higher second stable boundary, small a drives but high $\alpha$ does 
not. Also as in ideal MHD at large $\alpha$ (approaching the second stable boundary), the maximally unstable $\hat{\theta}$ does not occur at $\hat{\theta}=0$. Figure 3(a) shows the maximum growth rate and Fig. 3(b) the heat diffusion versus $\alpha$. Even well into the second ideal MHD regime at $\alpha \approx 3$ (At $\hat{s}=1, \alpha_{\text {first }}$ $\approx 0.5, \alpha_{\text {second }} \approx 2$.), there is no marked change in the ITG diffusion levels bearing in mind that this is an electrostatic $(\beta=0)$ simulation and thus somewhat artificial.
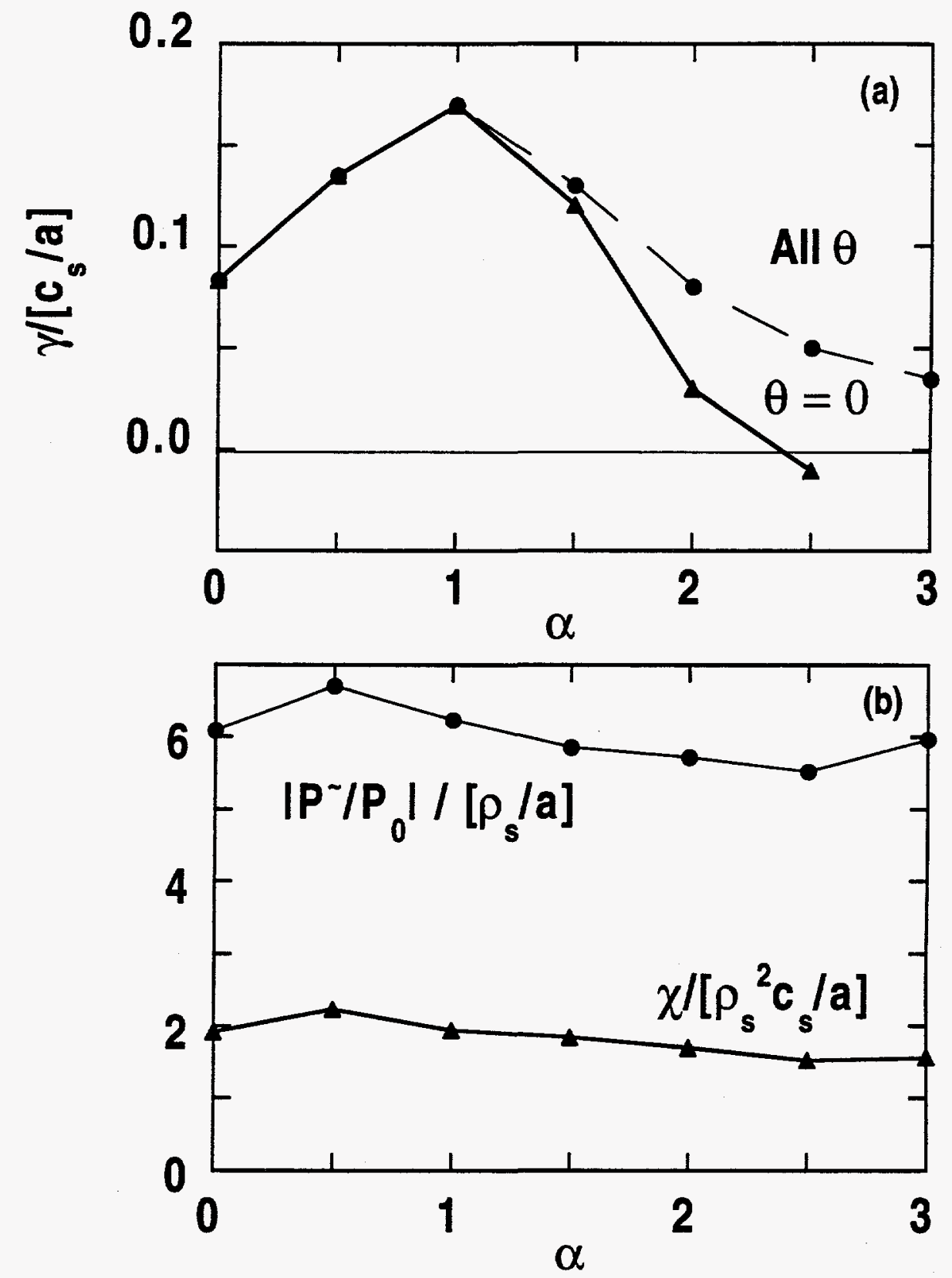

Fig. 3. Maximum growth rate (a) and diffusion (b) versus Shafranov shift $\alpha$. 
Going to vanishing shear at finite beta makes little sense in the usual $\hat{s}-\alpha$ model without average favorable curvature. In this case the critical beta for the ideal modes is zero at zero beta whereas in fact at low shear (say $\hat{s} \leq 0.2$ ) there is no local beta limit when the average favorable curvature or magnetic well is included. Here we ask what average favorable curvature does electrostatically. One may expect that since this subtracts directly from the curvature at $\theta=0$, the toroidal ITG modes driven by the curvature would have a larger driving rate. In fact small curvature $\left(\mathrm{L}_{\mathrm{T}} / \mathrm{R}\right)$ drives whereas very large curvature forces the ion response to adiabatic; thus the toroidal ITG instability (for $\mathrm{L}_{\mathrm{n}} / \mathrm{R}>1$ ) becomes stable at a critically large $\mathrm{LT}_{\mathrm{T}} / \mathrm{R}$. For example at a typical value for magnetic well $\mathrm{x}_{\mathrm{mw}}=0.5$, although the low $\mathrm{k}_{\mathrm{y}}$ modes have less drive or are more stable and the high $\mathrm{k}_{\mathrm{y}}$ modes are significantly more unstable, $\gamma_{\max }$ is almost unchanged (0.087 compared to 0.082$)$ at $\mathrm{a} / \mathrm{LT}=3$ and the heat diffusion is virtually unchanged. At $\mathrm{a} / \mathrm{LT}=$ 2.2 closer to the threshold of $1.8, \gamma_{\max }$ is actually larger $(0.037$ compared to 0.027$)$ and the transport is also larger ( 1.3 compared to 0.93$)$. We can conclude again at least near threshold (at moderator to strong shear) diffusion scales like the linear mixing length formula. Further although magnetic well has an extremely important effect on low shear in finite beta, it has a small or even slightly unfavorable effect at moderate shear an low beta.

\section{Critical rotational shear stabilization at weak magnetic shear}

We showed in Ref. 2 (see discussion of Fig. 7) that Doppler shear rates comparable to the maximum linear growth rate including the destabilization effect of parallel shear drive $\left(\gamma_{\mathrm{E}} \approx\right.$ $\left.\gamma_{\max }\right)$ is sufficient to cause the transport to vanish. We found this to be true at moderate shear $(\hat{s}=1)$ and even at vanishing shear $(\hat{s}=0)$. This appears to be at odds with the "convection rule" $\gamma_{\mathrm{E}} \approx \pi \hat{s} \gamma_{\max }$. The convection rule derives from the fact that linearly $E \times B$ rotational shear cause ballooning modes to rotate in their ballooning angle $\hat{\theta}$ at the rate $\gamma_{E} / \hat{s}$, thus one might expect to see stability if the mode rotates faster from $\hat{\theta}=0$, where it is most unstable, to $\hat{\theta}=\pi$, where it is stable, faster than it can grow. While this may be reasonable for moderate magnetic shear, the 
convection rule at weak shear would imply that even infinitesimal Doppler shear rates would be able to cause vanishing transport. However the convection rule is unlikely to hold at vanishing shear for two reasons. The first is that at weak shear, say $\hat{s}=0.1, \hat{\theta}=\pi$ is not stable. For example in the standard case at $\hat{s}=1, \gamma_{\max }=0.083$ at $\hat{\theta}=0$ and $\hat{\theta}=\pi$ is completely stable. However at $\hat{s}=$ $0.1, \gamma_{\max }=0.12$ at $\hat{\theta}=0$ and $\gamma_{\max }=0.10$ at $\hat{\theta}=\pi$. In the last case, although the mode is centered about $\theta=\pi$, its peak amplitude is at $\theta=-0.1 \pi$ and $\theta=0.1 \pi+2 \pi$, i.e. it lives in two the bad curvature regions. In fact there is little variation of growth rate with $\hat{\theta}$ at $\hat{s}=0.1$. The second reason that the convection rule may fail at even moderate shear is that the ballooning mode may be broken up by the turbulence before it has a chance to convect a significant distance in $\hat{\theta}$. Figure 4 shows an example of the convection rule partially or approximately holding at moderate to strong $\hat{s}$ but breaking down for weak shear $\left(\hat{s}<0.5\right.$ for a $\left./ L_{T}=3\right)$. It also breaks down at stronger driving or at least in the saturated temperature gradient regime (all $\hat{s}$ at $\left.a / L_{T}=4\right)$. We have not found a case in which $\gamma_{E}$ less than about half $\gamma_{\max }$ causes the transport to vanish.

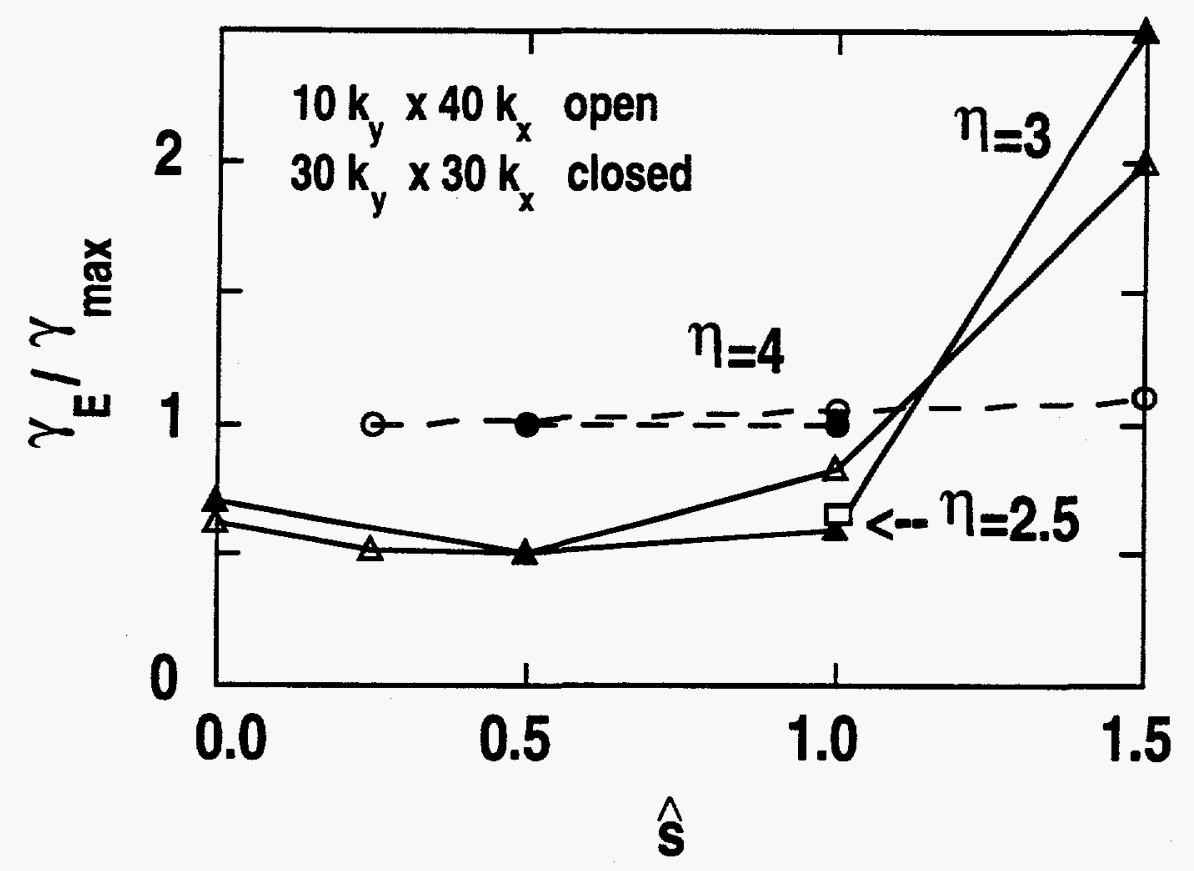

Fig. 4. Critical Doppler shear rate versus shear $\hat{s}$. 


\section{Turbulent rotational momentum transport and transport bifurcation}

The core of a tokamak normally achieves significant $E \times B$ or Doppler rotational shear to effect the stability and transport only when it spun up by beams which are tangentially directed. Because magnetic pumping in the poloidal direction prevents significant poloidal rotation, the rotation is almost purely toroidal. In this case the parallel shear which drives the ITG mode (see Fig. 7 of Ref 2.) is directly related to the Doppler shear rate by $\gamma_{P}=(R q / r) \gamma_{E}$ where $(R q / r)=$ $\mathrm{B}_{\phi} / \mathrm{B} \theta$. Thus if $(\mathrm{r} / \mathrm{Rq})$ is too low, the Doppler shear stabilization can not keep up with the parallel shear destabilization. As the rotational shear rate increases both the turbulent heat diffusion and the turbulent viscosity transporting the toroidal momentum and determining the rotation and rotational shear will decrease monotomically. However at some sufficently high $(\mathrm{r} / \mathrm{Rq})$ Doppler shear stabilization wins out over parallel shear drive. A transport bifurcation can result. Figure 5(a) shows a low $(\mathrm{r} / \mathrm{Rq})$ case $\gamma_{P}=12 \gamma_{E}$ without bifurcation and Fig. 5(b) shows a higher $(\mathrm{r} / \mathrm{Rq})$ case with $\gamma_{\mathrm{P}}=9 \gamma_{\mathrm{E}}$ with a momentum transport bifurcation at $\gamma_{E}=0.06$. In the latter case, the toroidal momentum flow $\Pi_{\phi x}$ required to sustain high rotations decreases with increased rotation; thus the plasma quickly spins to a higher rotational state at the same flow. The higher rotational state has a smaller heat diffusion and therefore can support a larger temperature gradient and hence improved confinement at the same momentum and heat (power) flow. This could be origin of the H- to VH-mode transition in DIII-D. ${ }^{12}$ It should be noted that this momentum transport bifurcation is likely the opposite extreme of the $\mathrm{L}-$ to $\mathrm{H}$-mode bifurcation at the extreme edge. There $E \times B$ rotation is nearly in balance with diamagnetic rotation and there is little change in the local plasma rotation; the bifurcation is within the heat transport system. A higher temperature gradient hence diamagnetic and therefore $E \times B$ rotation can have lower heat diffusion than a lower gradient state at the same heat flow. ${ }^{13}$ Clearly a mixture of heat and momentum transport bifurcation's are possible. 

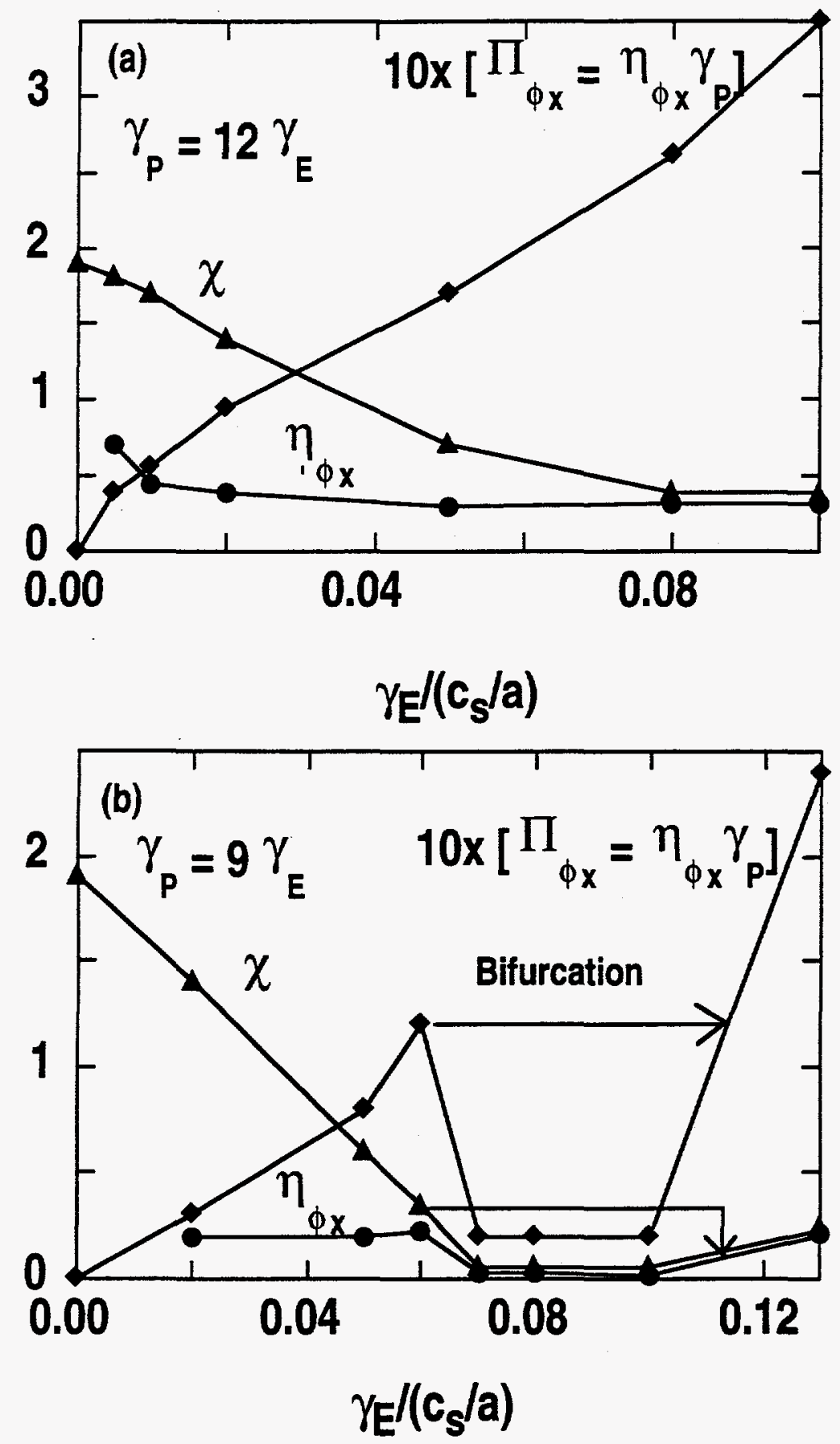

Fig. 5. Low $r /(R q)$ (a) high $r /(R q)$ (b) momentum bifurcation onset. 


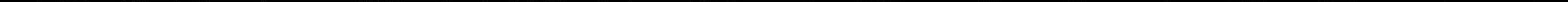




\section{LINEAR TESTS OF FINITE BETA TRAPPED ELECTRON GLF MODELS}

Our finite beta trapped electron GLF code has not yet been run to the nonlinear stage but we believe it gives a satisfactory representation of the linear mode stability in comparison to Kotschereuther's gyrokinetic stability (GKS) code. ${ }^{6}$ Figure 6 shows that it reasonably well reproduces the onset of the ideal ballooning mode limit near $\beta_{e}=0.0055$. Figure 7 shows the spectrum of growth rates in the collisionless limit at zero beta and at a beta value approaching the beta limit. It is apparent from the adiabatic electron points shown that the trapped electron physics has a significant destabilization effect on the ITG mode. At lower values of temperature gradient, the ITG ion branch can become stable and the normally subdominant electron trapped electron drift mode will remain unstable. Figure 8 shows the behavior of the collisional detrapping model in the electrostatic limit. Both the GLF and the GKS models should approach the adiabatic electron model (shown at right) at extreme collisionality where the trapped electrons are detrapped. The figure also shows favorable comparison of the simple GLF model with a 6moment ion and 3-moment trapped electron GLF model having a pitch angle scaterring operator developed by Beer. ${ }^{14}$

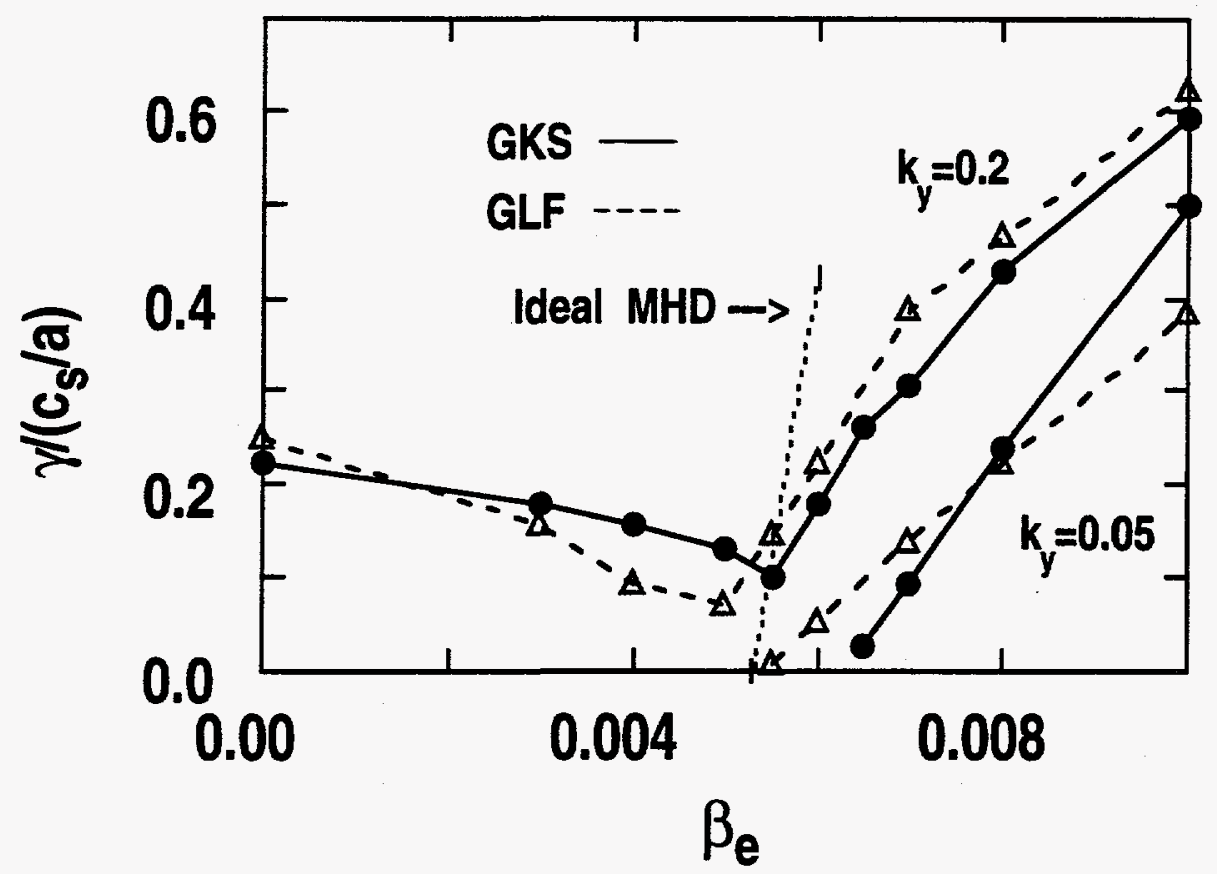

Fig. 6. Trapped electron model growth rate spectrum versus $\beta_{\mathrm{c}}$. 

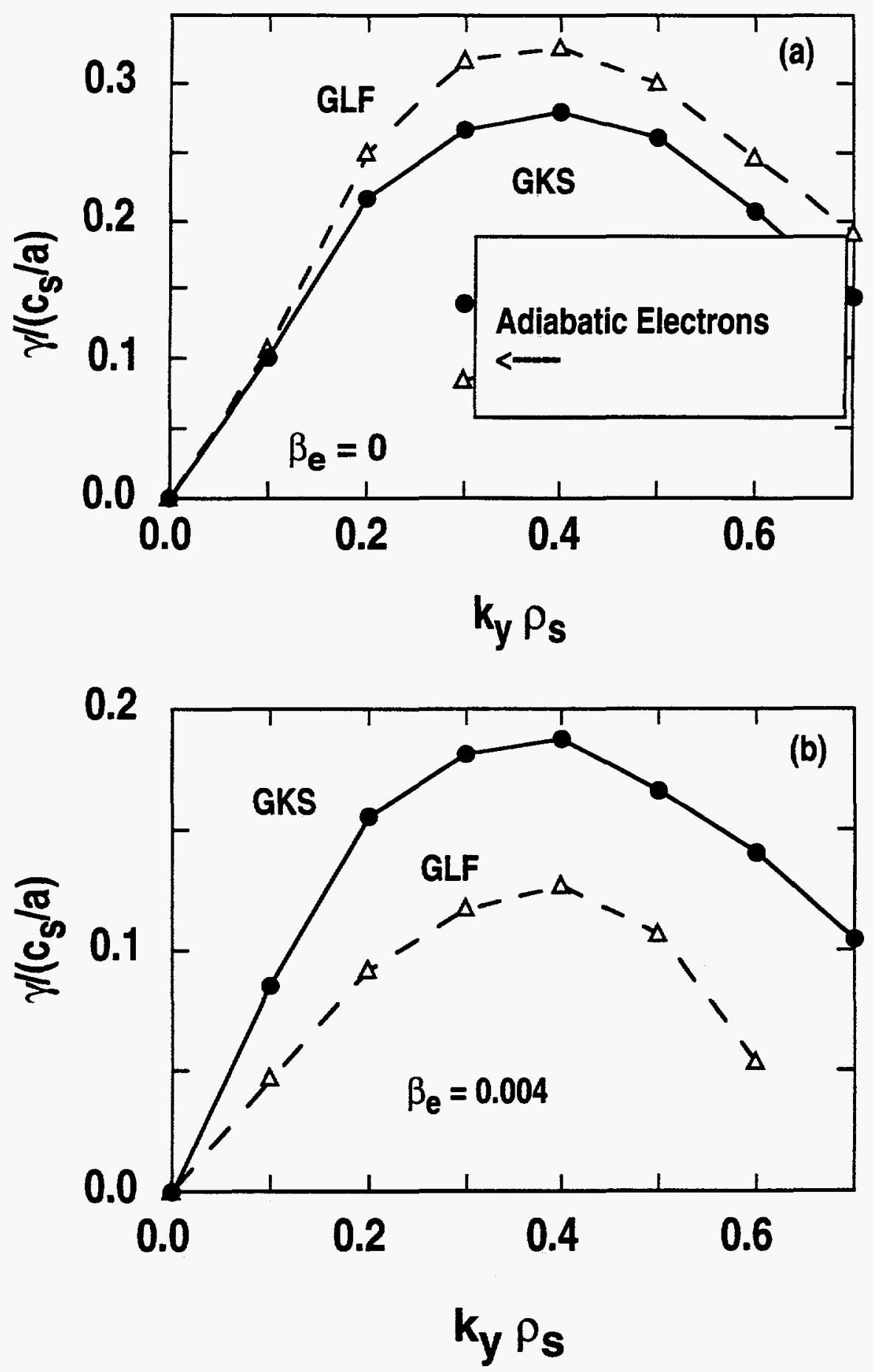

Fig. 7. Trapped electron model growth rate spectrum $\beta_{e}=0$ (a) $\beta_{e}=0.004$, (b) with $\beta_{\text {e-crit }}$ at 0.0055 . 


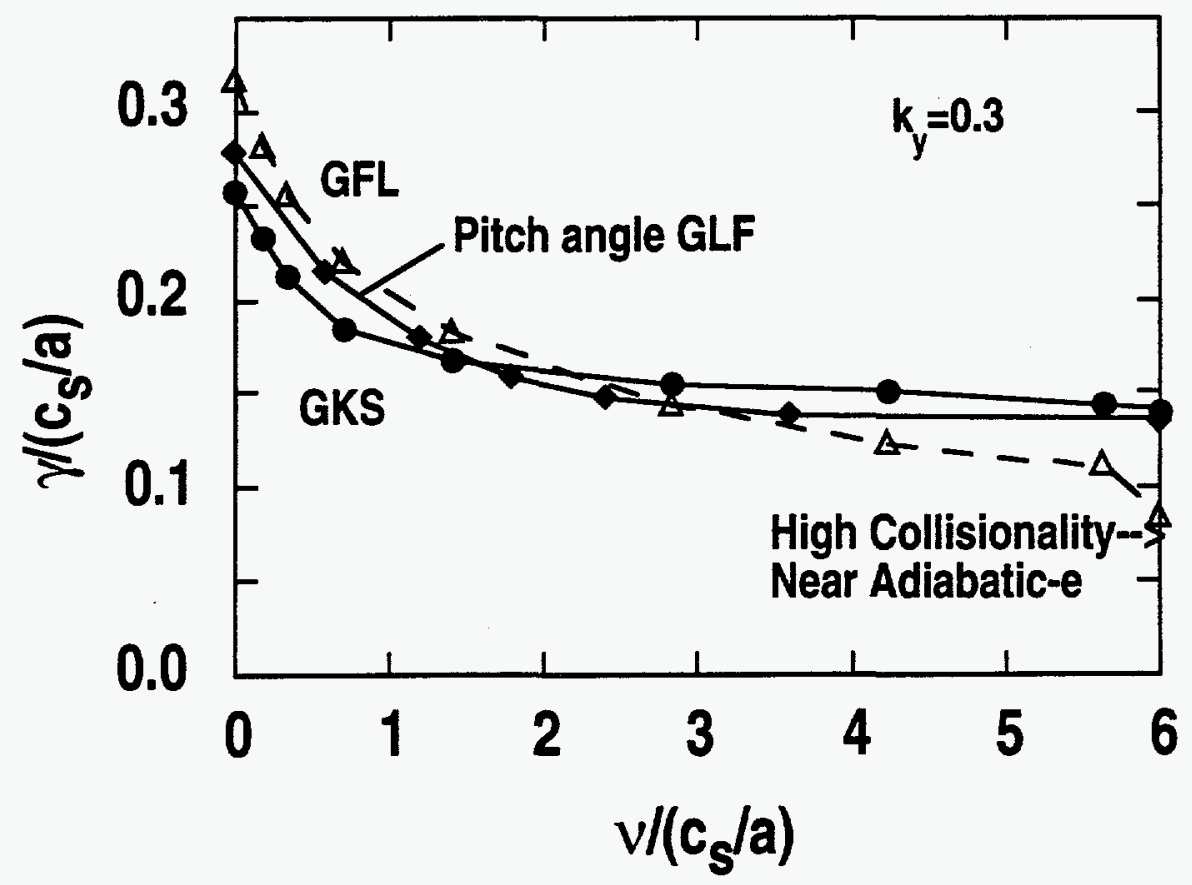

Fig. 8. Trapped electron model growth rate spectrum versus collision frequency $v$ at $k_{y}$ $=0.3$.

One of the most important effects of including the electron physics is that the radial mode physics can be treated dynamically rather than with a model. The saturation level of the $n=0$ radial modes appears to control the saturation level of the transport producing finite-n ballooning modes. Previous work ${ }^{2-5}$ assumed that since the electron motion along the field line is so rapid, the electrons will behave adiabatically and short out any deviations from the average potential $\mathrm{N}_{\mathrm{k}}^{\mathrm{e}}=\left(\phi_{\mathrm{k}}-\langle\phi\rangle_{\mathrm{k}}\right)$. In effect this assumes that the electron response $\mathrm{R}_{\mathrm{k}}^{\mathrm{e}}=\mathrm{N}_{\mathrm{k}}^{\mathrm{e}} / \phi_{\mathrm{k}}$ is close to 0 for radial modes which seems appropriate for $\mathrm{k}_{\|}$close to zero. [Actually $\mathrm{R}_{\mathrm{k}}^{\mathrm{s}} \equiv\left(\tilde{n}_{k}^{s} / \mathrm{n}_{0}\right) /\left(\mathrm{e}_{\mathrm{s}} \phi_{\mathrm{k}} / \mathrm{T}_{\mathrm{e}}\right)$ but this is the same as $\mathrm{N}_{\mathrm{k}}^{\mathrm{e}} / \phi_{\mathrm{k}}$ since there is no significant polarization.] The surprisingly, using the actual electron dynamics shows that $R_{k}^{e} \equiv-\left(T_{i} / T_{e}\right) R_{k}^{i}$ [from quasi-neutrality] tends to be closer to -1 at least in the case of purely passing electrons. This means the ions tend to behave adiabatically $\left(R_{k}^{i} \approx 1\right)$. Recall that radial modes are automatically $2 \pi$ periodic and require no images to make them physically periodic. $\langle\phi\rangle_{\mathrm{k}}$ is not zero and $\phi$ does not tend to zero at large $\theta$. For the case of trapped electrons, only the larger $k_{x}$ 
have $\mathrm{R}_{\mathrm{k}}^{\mathrm{e}}$ near -1 but in no case is $\mathrm{R}_{\mathrm{k}}^{\mathrm{e}}$ close to 0 . Since the nonlinear driving of radial modes is proportional to $1 /\left(\mathrm{R}_{\mathrm{k}}^{\mathrm{e}}+\mathrm{k}_{\mathrm{x}}^{2}\right)$ they will be less strongly driven with finite $\mathrm{R}_{\mathrm{k}}^{\mathrm{e}}$ than in the case of the adiabatic electron model. On the other hand they appear to be much less damped with $\gamma_{\mathrm{k}} \approx$ $-0.025 \mathrm{k}_{\mathrm{x}}^{2}$ for purely passing electrons or at least somewhat less damped with $\gamma_{\mathrm{k}} \approx-0.1 \mathrm{k}_{\mathrm{x}}$ in the trapped electron case compared to $\gamma_{\mathrm{k}} \approx-0.2 \mathrm{k}_{\mathrm{x}}$ for adiabatic case [see Ref. 2 Fig. 2(d)]. 


\section{CONCLUSIONS}

Beyond the conclusions stated in Ref. 2 and reviewed in Section I, the present paper has arrived at additional conclusions: Although eddies are highly elongated in the radial direction long time radial correlation lengths are short and comparable to poloidal lengths. Although transport at vanishing shear is not particularly large, transport at reverse global shear is significantly less. Electrostatic transport at moderate shear is not much effected by inclusion of local shear and average favorable curvature. Transport is suppressed when critical $E \times B$ rotational shear is comparable to the maximum linear growth rate with only a weak dependence on magnetic shear. Self consistent turbulent transport of toroidal momentum can result in a transport bifurcation at large enough $\mathrm{r} /(\mathrm{Rq})$. We believe the new formulation in the paper for treating finite beta GLF models with collisionally detrapped trapped electrons and BMR numerical methods for treating the fast parallel field motion of the untrapped electrons are in satisfactory linear agreement with gyrokinetic stability codes and will allow a general and more physical simulations up to the ideal beta limit. 


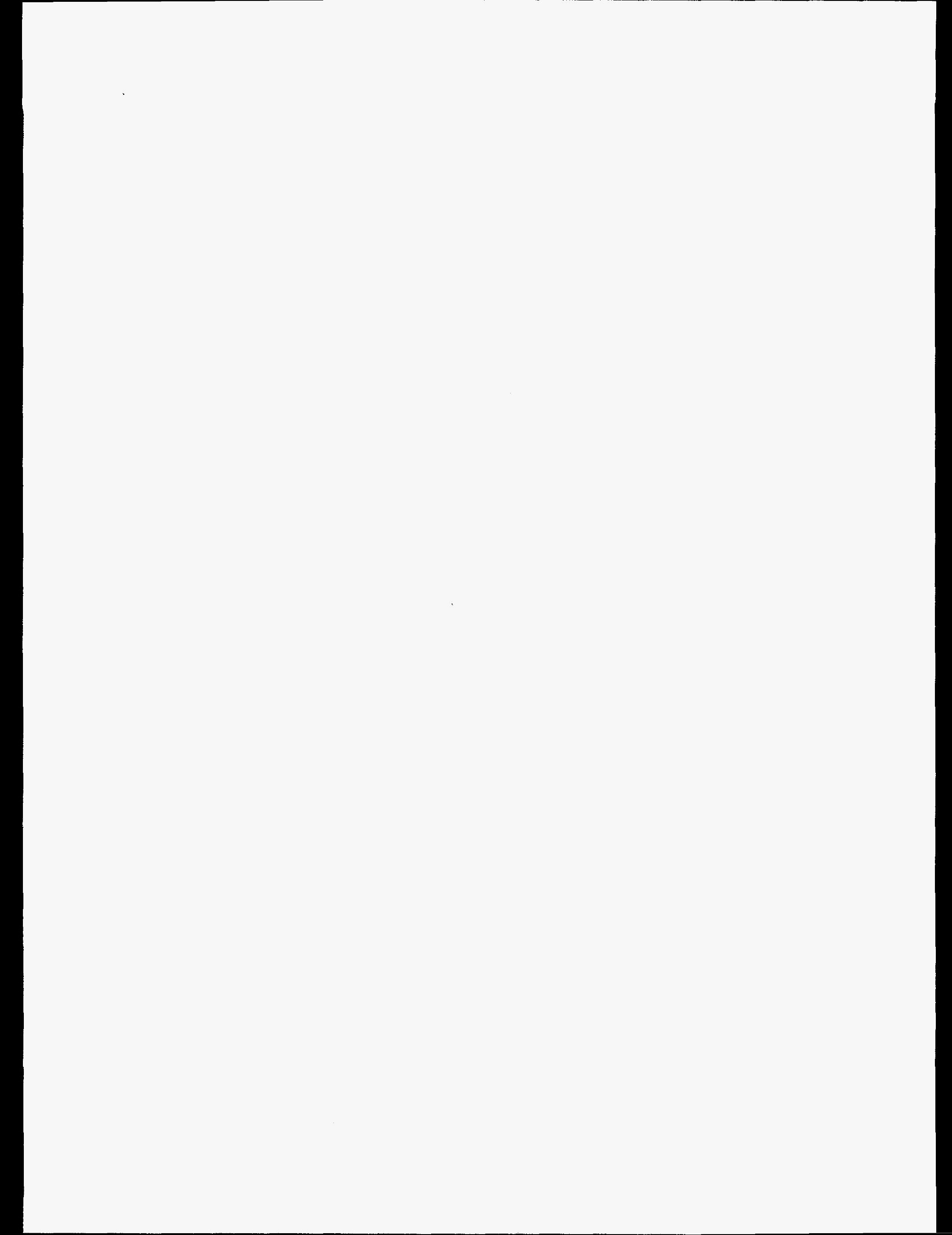




\section{REFERENCES}

${ }^{1}$ R. E. Waltz, R. R. Dominguez, and G. W. Hammett, Phys. Fluids B 4, 3138 (1992).

${ }^{2}$ R. E. Waltz, G. D. Kerbel, and J. Milovich, Phys. Plasmas 1, 2229 (1994).

${ }^{3}$ W. Dorland, M. Kotschenreuther. M. A. Beer, G. Hammett, R. E. Waltz, R. R. Dominguez, P. M. Valanju, W. H. Miner, Jr, J. Q. Dong, W. Horton, F. L. Waelbroeck, T. Tajima, M. J. Le Brun in Proc. 15th Intnl. Conf.. on Plasma Phys. and Contr. Nucl. Fusion Research, Seville, Spain 1994 (International Atomic Energy Agency, Vienna,) to be published, paper IAEA-CN60/D-P-I-6.

${ }^{4}$ M. Beer, G. W. Hammett,W. Dorland, and S. Cowley, Bull. Am. Phys. Soc. 37, 1478 (1992).

5W. Dorland. G. W.Hammett, T. S. Hahn, M. A. Beer, Bull. Am. Phys. Soc. 37, 1478 (1992); see also Proc. US/Japan Workshop on Ion Temperature Gradient Driven Turbulent Transport, edited by W. Horton, M. Wakatani, and A. Wootton (American Institute of Physics, New York), p. 277.

${ }^{6}$ M. Kotschenreuther, Bull. Am. Phys. Soc. 37, 1432 (1991); see also M. Kotschenreuther, G. Rewoldt, and W. M. Tang, Princeton Plasma Physics Laboratory Preprint PPPL-2986 submitted to Comp. Phys. Commun.

${ }^{7}$ O. T. Kingsbury and R. E. Waltz, Phys. Plasmas 1, 2319 (1994).

${ }^{8}$ S. C. Cowley, R. M. Kulsrud, R. Sudan, Phys. Fluids B 3, 2767 (1990). 
${ }^{9}$ R. E. Waltz and A. H. Boozer, Phys. Fluids B 5, 2201 (1993).

10P.N. Brown and A.C.Hindmarsh,, SIAM J. Num. Anal. 23, 610 (1986).

${ }^{11}$ R.J. Fonck, G. Cosby, R.D. Durst, S.F. Paul, N. Bretz, S. Scott, E. Synakowski, and G. Taylor, Phys. Rev. Lett. 70, 3736 (1993).

${ }^{12}$ R. J. La Haye. C.L. Rettig. R. J. Groebner, A. W. Hyatt, and J. T. Scoville, Phys. Plasmas 1, 373 (1994).

${ }^{13}$ G. M. Staebler, F. L. Hinton, J. C. Wiley, R. R. Dominguez, C. M. Greenfield, P. Gohil,T. K. Kurki-Suonio, and T. H. Osborne, Phys. Plasmas 1, 909 (1994).

14M. Beer, Princeton University Ph. D. Thesis 1994. 


\section{ACKNOWLEDGMENTS}

We appreciate numerous contributions from Drs. M. Beer (PPPL), B. Dorland, and M. Kotschenreuther (IFS). We wish to thank Dr. O.T. Kingsbury (UCSD) for numerical assistance. This work is supported in part by the High Performance Computing and Communications Initiative (HPCCI) Grand Challenge Numerical Tokamak Project. We are grateful to the Los Alamos Advanced Computing Laboratory for use of the CM5. This work is sponsored by the U.S. Department of Energy under Grant No. DE-FG03-92ER54150 and Contract Nos. W-7405-ENG-48, and DE-AC02-76-CHO-3073. 